Canadian

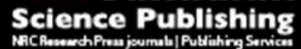

Canadian Journal of Physiology and Pharmacology Revue canadienne de physiologie et pharmacologie

\title{
Role of Risk Stratification and Genetics in Sudden Cardiac Death
}

\begin{tabular}{|r|l|}
\hline Journal: & Canadian Journal of Physiology and Pharmacology \\
\hline Manuscript ID & cjpp-2016-0457.R1 \\
\hline Manuscript Type: & Critical Review \\
\hline Date Submitted by the Author: & $19-$ Sep-2016 \\
\hline Complete List of Authors: & $\begin{array}{l}\text { Rai, Vikrant; Creighton University School of Medicine, Department of } \\
\text { Clinical \& Translational Science } \\
\text { Agrawal, Devendra; Creighton University School of Medicine, Department } \\
\text { of Clinical \& Translational Science }\end{array}$ \\
\hline Keyword: & $\begin{array}{l}\text { Sudden cardiac death, coronary artery disease, heart failure, Arrhythmias, } \\
\text { Atrial fibrillation }\end{array}$ \\
\hline &
\end{tabular}




\title{
Role of Risk Stratification and Genetics in Sudden Cardiac Death
}

\author{
Vikrant Rai $^{1}$ and Devendra K. Agrawal ${ }^{1}$ \\ ${ }^{1}$ Department of Clinical and Translational Science, Creighton University School of Medicine, \\ Omaha, NE 68178
}

*Corresponding author

Devendra K. Agrawal, Ph.D. (Biochem), Ph.D. (Med. Sciences), MBA, MS (ITM), FAAAAI,

FAHA, FAPS, FIACS

Professor and Chairman, Department of Clinical \& Translational Science

The Peekie Nash Carpenter Endowed Chair in Medicine

Senior Associate Dean for Clinical \& Translational Research

Creighton University School of Medicine

CRISS II Room 510, 2500 California Plaza

Omaha, NE, 68178, USA

Tel: (402) 280-2938

Fax: (402) 280-1421

E-mail:1kagr@,creighton.edu

Running title: Risk stratification in sudden cardiac death 


\begin{abstract}
Sudden cardiac death (SCD) is a major public health issue due to its increasing incidence in the general population and the difficulty in identifying high-risk individuals. Nearly 300,000-350,000 patients in the United States and 4- to 5 million patients in the world die from SCD. Coronary artery disease and advanced heart failure are the main etiology for SCD. Ischemia of any cause precipitates lethal arrhythmias, and ventricular tachycardia and ventricular fibrillation are the most common lethal arrhythmias precipitating SCD. Pulse-less electrical activity, brady-arrhythmia and electromechanical dissociation also result in SCD. Most sudden cardiac deaths occur out-of-the-hospital setting, so it is difficult to estimate the public burden, which results in overestimating the incidence of SCD. The insufficiency and limited predictive value of various indicators and criteria for SCD result in the increasing incidences. As a result, there is a need to develop better risk stratification criteria and find modifiable variables to decrease the incidence. Primary and secondary prevention and treatment of SCD need further research. This critical review is focused on the etiology, risk factors, prognostic factors and importance of risk stratification of SCD.
\end{abstract}

Key words: Sudden cardiac death, Coronary artery disease, Heart failure, Arrhythmias, Atrial fibrillation, Ventricular fibrillation, Channelopathies, Risk stratification, Prevention 


\section{Introduction}

Sudden cardiac death $(\mathrm{SCD})$ is defined as a sudden, unexpected natural death from a cardiac cause within a very short duration of time, usually $\leq 1 \mathrm{hr}$ in an individual without and previous cardiac disease (Myerburg et al. 1997; Zipes and Wellens 1998). It is also defined as death due to a cardiac cause occurring in home or during transportation to the hospital, in the emergency room or dead on arrival to the emergency (Every et al. 1997; Iribarren et al. 1998). According to the World Health Organization, any unexpected death within 1 hour if witnessed or, if not witnessed, within 24 hours in a person seen alive and symptom-free is termed as SCD (Chugh et al. 2004). However, this definition leads to misclassification in cases of death from other causes, such as pulmonary embolism and considered to be due to cardiac causes, resulting in overestimation of the problem. Therefore, there is a need to include additional criteria to get a better picture of SCD's prominence in society. SCD is the most common and a major public health problem due to its lethality. Its prevalence is likely to increase because the cases of heart failure and coronary artery disease (CAD) are increasing. SCD is of concern due to its high incidence and sudden, unexpected nature, along with its successful rate of resuscitation (Myerburg et al. 1997; Zipes and Wellens 1998). Coronary artery disease, cardiomyopathy, cardiac rhythm disturbances, or hypertensive heart disease are risk factors for SCD (Roberts 1990). SCD most commonly results from cardiac arrest in a person with CAD in settings of reduced $(<30 \%)$ ejection fraction (EF) (Figure 1).

Lethal arrhythmias in the background of structural heart disease or CAD can also lead to cardiac arrest, resulting in SCD. Ventricular tachycardia (VT) progressing to ventricular fibrillation (VF) and circulatory collapse is the main mechanism for SCD (de Luna et al. 1989; Myerburg et al. 1997; Zipes and Wellens 1998). Increasing trends in the incidence of heart disease by 2020 (Murray and Lopez 1997), the dramatic increase in the incidence of diabetes and CAD in developing nations (Okrainec et al. 2004), and the increasing incidence 
of decreased survival from SCD in developed nations (Chugh et al. 2004) raise concern. Even with a focus on cardiac disease management in the emergency room, the poor understanding of the etiology and mechanism of fatal arrhythmias and the delay in the development of effective measures of risk stratification and prevention of SCD result in an increasing incidence of SCD (Myerburg 2002). This review discusses the etiology, risk factors, prognostic factors, established and developing criteria for risk stratification and modalities available for primary and secondary prevention of SCD.

\section{Sudden cardiac death: A social burden}

Important variables to study the epidemiology of any disease are cause of death and demographic variations, such as sex, age, and ethnicity and race. Different coding systems, insufficient information, or unavailability of detailed clinical information from the hospital record and death certificate, not to mention patient symptoms and exact cause of death on the death certificate are the common causes of variations in reporting of SCD. Overrepresentation of $\mathrm{CAD}$ as a cause for $\mathrm{SCD}$, the existing criteria of $\mathrm{SCD}$ as death in $\leq 1$ hour, and not specifying and mentioning the time of onset of symptoms lead to over-representation of certain factors as a cause of SCD and underestimation of SCD's societal burden (Zheng et al. 2001). Further, the unpredictable manner of disease, lack of a standard definition, and non-cardiac causes of sudden death (e.g. pulmonary embolism) make real assessment of SCD difficult.

Most SCD studies have overestimated incidence by as much as $200-300 \%$ (Arking et al. 2004). Challenges in collecting the accurate data due to the lack of clarity in regard to circumstances of deaths, vague histories, classification of deaths after the prolonged chronic illness and deaths during the hemodialysis in end-stage renal disease patients as SCD, and not reporting the deaths in patients with implantable cardioverter-defibrillator, or due to long QT

syndrome as SCD contribute to flawed data. Further, dependence of the statistical data 
collection and analysis solely on the retrospective studies and autopsy negative sudden cardiac deaths also contribute to overestimation of the SCD (Harmon et al. 2015; Postema and Wilde 2008; Rao 2013) (Figure 1). However, getting the information from hospital records and autopsy documents, information from first responder and using a questionnaire-based approach to collect histories may supplement the death certificate in collecting the better SCD data (Rao 2013).

Study by Zheng et al. (Zheng et al. 2001) on the incidence of SCD in US population in between 1989 and 1998 found that, in 1998, SCD accounted for 63.3\% of the total deaths with an increasing incidence. It was also found that the incidence of SCD varies with age, sex, race, and ethnicity. An increasing incidence in SCD among women was of concern, indicating that special attention was needed for women (Chugh et al. 2004). Contrary to this, however, the Framingham Heart Study, with its 38-year follow-up has suggested that the incidence of SCDs is higher in men (45\%) as compared to women (32\%) (Kannel et al. 1998). Many retrospective, cohort, prospective, and community-based studies and national surveys have reported the incidence of SCD as 51-53/100,000, an average of 1 per 1,000 persons, all indicating the social burden of SCD. The annual U.S incidence of SCD is approximately $300,000-350,000$ cases; and worldwide, it is approximately $4-5$ million cases per year. It has been reported that the incidence of SCD increase with age and varies with gender, calendar month, and day of the week (Birati et al. 2016; Byrne et al. 2008; Chugh et al. 2004; Stecker et al. 2006; Straus et al. 2004).

\section{Etiology of sudden cardiac death}

\subsection{Structural heart disease and conduction defects}

CAD is attributed to approximately $80 \%$ of all cases of SCD (Chugh et al. 2004; Myerburg and Junttila 2012). However, out of these $80 \%$, only $13 \%-20 \%$ of cases will have sudden cardiac arrest (Kannel et al. 1987). Common precipitating events for SCD are VT, 
VF, bradycardia or electromechanical dissociation (Turakhia and Tseng 2007). Ischemia caused by occlusion of the coronary artery or plaque rupture will precipitate polymorphic ventricular arrhythmias. Left ventricular dysfunction and post-infarcted ischemic cardiomyopathy also may lead to monomorphic ventricular arrhythmias. Untreated arrhythmia may progress to VF, resulting in SCD. VF can also be precipitated by a timely mechanical blow to a normal heart through a phenomenon called commotio cordis (Ota and Bratincsak 2014; Link and Estes 3rd 2007) (Figure 1). The incidence of SCD increases 2- to 4-fold in the presence of CAD and 6- to 10-fold in the presence of structural heart disease (Podrid and Myerburg 2005) (Figure 2). Ventricular arrhythmia/VF or pulseless electrical activity (PEA) account for majority of SCDs (Luu et al. 1989; Myerburg et al. 1997; Zipes and Wellens 1998). Although VF is the most common arrhythmogenic etiology for SCD (de Luna et al. 1989), recent trends suggest a declining incidence of SCD due to VF and an increasing incidence due to PEA, making it the main arrhythmia responsible for SCDs (Dorian et al. 2002; Parish et al. 2003) (Table 1). In a heart with left ventricular failure or advanced congestive heart failure, bradycardia or PEA is the main precipitating event for SCD. In patients with implantable cardioverter defibrillators (ICD), arrhythmia accounts for 20 to $35 \%$ of deaths (Mitchell et al. 2002).

Cardiomyopathies (dilated cardiomyopathies, hypertrophic cardiomyopathy), myocardial infiltrative diseases (sarcoidosis and amyloidosis) and arrhythmogenic right ventricular dysplasia account for $10 \%-15 \%$ of SCDs. The remaining $5 \%-10 \%$ of SCDs are attributed to electrical or congenital (prolonged QT syndrome, Brugada syndrome (Korte et al. 2015), catecholaminergic polymorphic ventricular tachycardia, coronary anomalies, cyanotic/noncyanotic diseases) abnormalities of heart (Figure 3). Spontaneous coronary artery dissection in the left descending coronary artery and anomalous origin of the left coronary artery from the pulmonary artery can also precipitate SCD (Aksakal et al. 2014; 
Pachon et al. 2015). Dilatation of a coronary artery segment to a diameter of more than 1.5fold its normal size is defined as coronary artery aneurysm (CAA), and contained rupture of mycotic CAA in the left circumflex coronary artery has been reported as a cause of myocardial ischemia (MI) or SCD (Joshi et al. 2015). Heart failure of any cause, as well as genetic abnormalities of the heart along with $\mathrm{CAD}$, can also cause predisposition to SCD. Common causes of SCD in the young population are acute ischemic heart disease, unspecified cardiovascular disease, cardiomyopathy and dysrhythmia, and in the elderly population include chronic ischemic heart disease and heart failure (Zheng et al. 2001).

Sympathetic and parasympathetic dysfunction of the heart, not only in the infarcted area but also in regions apical to the infarct is caused by myocardial infarction, probably due to the interruption of traversing afferent and efferent nerve fibres from the infarct region. This abnormality in the autonomic nervous system leading to the refractoriness may result in SCD. Heart failure and ventricular dilation/hypertrophy can cause similar refractoriness. Refractoriness leads to ventricular arrhythmias and SCD. The protective effect of vagal stimulation on ventricular arrhythmia is inconclusive. However, the preventive effects of exercise conditioning on ventricular fibrillation have been demonstrated in dogs, but needs further research (Zipes and Rubart 2006; Zipes and Wellens 1998). Sympathetic stimulation or activation of heart influences the risk of ventricular arrhythmia and SCD, and is mediated by the $\beta-2$ adrenergic receptor. Further polymorphism of the $\beta-2$ adrenergic receptor can play a role in SCD. Gln27 carriers are at increased risk compared to Glu27. However, Gly16Arg carriers are not associated with SCD (McNamara et al. 2002). Polymorphism of the $\beta-2$ adrenergic receptor plays a role in SCD risk, and there may be different risk and survival rate for different genotypes (Lanfear et al. 2005; Sotoodehnia et al. 2006). Similarly, the polymorphism of the cardiac sodium channel gene can play a role in risk and survival in SCD (Burke et al. 2005; Chen et al. 2007). 


\subsection{Channelopathies}

Though the heritability of SCD remains poorly understood, polymorphism and mutation in various genes and the correlation of CASQ2, GPD1L, KCNQ, KCNH2 (p.F29L), SCN5A (p.R1193Q), KCNE1, KCNE2, $\beta$-2AR (Gln27Glu), $\beta 1$ AR, $\alpha_{2 \mathrm{~B}}$-AR, IL-18, GPIa, Factor V Leiden, GPIb $\alpha$, GPIIIa „PT 20210A, REN, AGTR1,AGTR2,ACE2, BDRK2, AGT, ACE, and KNG1 with SCD have been studied (Deo and Albert 2012). These mutations lead to conduction defects and arrhythmias (long QT syndrome: 90\% of the LQTS-related mutations involve SCN5A, KCNH2, KCNQ1, KCNE1, KCNE2, and KCNJ2) which may cause predisposition to SCD (Christiansen et al. 2014). More than 90\% of cases of SCD are due to mutation or polymorphism in KCNQ1 (Long QT type-1), KCNH2 (Long QT type-2), and SCN5A (Long QT type-3) (Kauferstein et al. 2013 ; Kwon et al. 2012). These mutations or polymorphisms lead to alteration in sodium and potassium ion channels and gap junctions (Figure 1).

Ankyrin-B syndrome due to mutation in the ANK2 gene results in loss of function of the ankyrin-B protein, a protein regulating expression and localization of cardiac ion channels and transporters. This results in abnormal regulation of intracellular sodium and calcium and predisposition for ventricular arrhythmia including torsades de pointes. In such patients, QTprolonging drugs should be avoided and a permanent pacemaker for sinus node dysfunction or cardiac defibrillator should be used to decrease risks of SCD (Robaei et al.2015).

Andersen-Tawil Syndrome (ATS) due to mutation in gene $\mathrm{KCNJ} 2$, encoding the protein for rectifier potassium channel Kir2.1, is a type of congenital long QT syndrome having a high risk of SCD. Prolonged Q-U interval, ventricular arrhythmias, periodic paralysis and mild facial or skeletal abnormalities characterize ATS (Marquez et al. 2015). Kostera-Pruszczyk et al. (Kostera-Pruszczyk et al. 2014) reported three novel KCNJ2 mutations, c. 155G $>$ T (G52V), c.412G $>$ A (E138K), and c.436G $>$ C (G146R), in ATS patients, 
leading to high risk for cardiac symptoms. Mutation in human ether-a-go-go-related gene (hERG, KCNH2) which encodes Kv11.1, the pore-forming unit of rapidly activating delayed rectifier potassium channel or its variant hERG/p.Arg148Trp (R148W), in the heterozygous state can predispose the person to an increased risk of SCD (Sanguinetti 2012; Mechakra et al. 2014). Mutation in the KCNH2 gene (loss of function) and KCNQ1 is also associated with epilepsy. Unexplained deaths in epileptic patients can be due to long QT syndrome causing fatal arrhythmias ( Goldman et al. 2009; Partemi et al.2013).

Mutation in the SCN5A gene may lead to loss-of-function of the sodium channel, as in Brugada syndrome, or to gain-in-function as in prolonged QT syndrome, both leading to arrhythmia. Both loss-of-function and gain-of-function properties in the major cardiac sodium channel $\alpha$ subunit $\left(\mathrm{hNa}_{\mathrm{v}} 1.5\right)$ can occur due to SCN5A channelopathy with lysine at position 1620, and will lead to impaired impulse propagation and long QT syndrome (Surber et al. 2008). Similarly, the genetic variant of Nav1.5-Arg689 can precipitate arrhythmia and SCD (Sottas et al.2013). Further, the type of mutation (M-missense mutation or T-mutation causing premature truncation of protein) can also affect the severity of disease. Loss-offunction SCN5A channelopathies $\mathrm{T}$ and $\mathrm{M}_{\text {inactive }}\left(>90 \%\right.$ peak $\mathrm{I}_{\mathrm{Na}}$ reduction) mutation cause a more severe phenotype than $\mathrm{M}_{\text {active }}\left(\leq 90 \%\right.$ peak $\mathrm{I}_{\mathrm{Na}}$ reduction) mutation and are associated with a more severe conduction disorder (Meregalli et al. 2009). Recently, the p.D1690N mutation has been described in the pathogenesis of the Brugada syndrome due to the mutant-induced changes contributing to the loss of function of Nav1.5 channels (Zeng et al. 2016). Conduction defects and arrhythmias have been demonstrated in SCN5A ${ }^{\text {E558X/+ }}$ pig models resembling human sodium channelopathies, by introducing the nonsense mutation found in Brugada syndrome (Park et al.2015).

Cav-3, expressed by the caveolin-3 gene, is the main component of caveolae, a plasma membrane domain regulating cellular process related to cardiac excitability like 
calcium homeostasis, signal transduction, trafficking and cellular response to injury. Any variation in expression of Cav-3 may have a significant impact on the signaling pathway in the heart. The Cav-3 V821 variant may cause decreased activation of extracellular signalregulated kinase (ERKs) with a detrimental effect on cell viability and susceptibility to SCD (Lariccia et al. 2014) and an increase in the late sodium current similar to long QT syndrome type-3 (Vatta et al. 2006). Similarly the mutation in the Cav 1.2 channel gene may cause gain-of-function in patients with Timothy syndrome (prolonged QT interval) and loss-offunction in the Brugada syndrome (short QT interval), both causing lethal arrhythmias and SCD (Liao and Soong 2009).

The L-type calcium channel $\left(\mathrm{Ca}_{\mathrm{v}} 1.2\right)$ is encoded by the CACNA1C gene. Genetic variants of this gene with defects in the cell surface trafficking of the $\mathrm{Ca}_{\mathrm{v}} \alpha 2 \delta 1$ mutant downregulate the L-type $\mathrm{Ca}^{++}$current and may precipitate arrhythmias, leading to SCD (Bourdin et al. 2015). Similarly a loss-of-function mutation in the CACNA1C gene associated with familial SCD was described with the Brugada syndrome phenotype combined with shorter than normal QT intervals (Antzelevitch et al. 2007).

Drowning or swimming is a risk factor for sudden death in children and may precipitate arrhythmias; some specific mutations predispose the heart for arrhythmia. Long QT syndrome type-1 (LQT1) is caused by a mutation in the KQT-like voltage gated potassium channel-1 gene, leading to a decrease in slowly acting repolarizing potassium currents and long QT interval. Studies suggest that swimming-triggered cardiac events are pathognomonic for LQT1. There may be a sympathetic dominance over parasympathetic dominance due to cold water exposure, exertion, and facial immersion in water. Increased sympathetic activities will quickly raise the heart rate, but due to reduced rectifying potassium channel activity, the necessary QT shortening is prevented. Catecholaminergic polymorphic ventricular tachycardia caused by a mutation in the cardiac ryanodine receptor 
channel (RyR2) gene leading to calcium leakage from the sarcoplasmic reticulum of the cardiac myocyte has also been correlated with swimming-related SCD events of due to arrhythmia in children (Kenny and Martin 2011), SCD in young adults (Arakawa et al. 2015), and idiopathic ventricular tachycardia in adults (Akilzhanova et al. 2014).

Cheng et al. (Cheng et al. 2009) reported a mutation in $\alpha 1$-syntrophin (SNTA1) as a novel cause of long QT syndrome in sudden death infant syndrome (SIDS), and Tan et al. (Tan et al. 2010) suggested a mutation in the $\beta$ subunit of the $\mathrm{Na}_{\mathrm{v}} 1.5$ cardiac sodium channel as a cause of arrhythmia in SIDS. Mutations not only in ion channels but also in cardiac gap junction channels may cause conduction defects and lead to sudden death in children (SIDS). A mutation in human Connexin43 ( $\mathrm{Cx} 43)$, a major gap junction protein, can cause loss of function due to a loss-of-function mutation $(\mathrm{Cx} 43 \mathrm{E} 42 \mathrm{~K})$, resulting in sudden death (Lubkemeier et al. 2015 ; van Norstrand et al. 2012). It has also been proposed that loss-offunction sodium channelopathies in children can result in Brugada syndrome and conduction diseases. Such patients are diagnosed by cardiac symptoms, family history, and electrophysiological activity. Arrhythmias in such children can be precipitated by fever and vaccination. $\beta$-blockers may have a preventive role in mild cases and ICD in severe cases (Chockalingam et al. 2012). Recently, a novel mutation in Laminin, LMNA (c.871G>A, p.E291K) associated with familial dilated cardiomyopathy and SCD has been reported (Alexandra et al. 2015). Similarly the association between the CAV1 variant rs3807989 and AF (Chen et al. 2015), and the possible pathogenic role of tintin variants (Campuzano et al. 2015) have been discussed and need further research.

\section{Risk factors for sudden cardiac death}

Common risk factors for SCD include hypertension, diabetes, hypercholesterolemia, alcohol, smoking, epilepsy and use of non-steroidal anti-inflammatory drugs (NSAIDs). Smoking is the main risk factor in the younger female population, and hypertension, diabetes, 
and hypercholesterolemia are the main risk factors in the elderly female population (Burke et al. 1998). Diabetes is a risk factor for SCD, and a missense mutation in the GPD1L gene may cause long QT syndrome (Figure 1). The electrophysiological features of malignant ventricular arrhythmia due to Brugada syndrome in diabetics may be masked, so at-risk patients should be critically evaluated (Skinner et al. 2014). The hypercoagulable state can be a risk factor for $\mathrm{MI}$ or $\mathrm{SCD}$, and homozygosity of the $4 \mathrm{G}$ allele of the plasminogen activase inhibitor type 1 gene has been reported as a cause of aborted SCD (Phillips et al. 2015). Diabetes is of concern because the symptoms of cardiac arrest are atypical in diabetes and even cardiac arrest may go silent (silent cardiac arrest). There is a need to stress the importance of finding predictors of SCD in diabetic patients. Diabetes is not only a strong risk factor for SCD, it also affects other risk factors of SCD, such as age, sex, body mass index, family history, tobacco use, cholesterol level, triglyceride level, and blood pressure changes (Albert et al. 2000; Albert et al. 2003). Diabetic cardiomyopathy and prolonged corrected QT (QTc) in diabetics are markers for diabetes-associated SCD (Rana et al. 2005).

Co-morbid conditions like obesity and epilepsy can also contribute to SCD (Figure 1). Several studies have proposed an association between long QT syndrome and SCD in related individuals (Keating and Sanguinetti 2001; Splawski et al. 1997;) and an association of QTc with SCD in non-related individuals (Goldenberg et al. 2006; Straus et al. 2006). Abnormal QTc prolongation on the electrocardiogram should be viewed as an independent risk factor for sudden cardiac death (Straus et al. 2006). Morbid obesity can increase the risk of SCD up to 40-fold (Chugh et al. 2000) and epilepsy up to 24-fold (Ficker et al. 1998). Along with diabetes and epilepsy, prolonged QT interval can be present in Takayasu arteritis. Due to the probability of involvement of coronary arteries, any patient presenting with cardiac syncope should be examined in detail to rule out risk for SCD (Hanna et al. 2015). 
Socioeconomic status is an important factor while studying a disease pattern and it has a persistent effect on disease development. Correlation studies for socioeconomic status and heart disease $(\mathrm{SCD})$ found a $30 \%-80 \%$ increase in the incidence of SCD in populations living near lower socioeconomic status neighborhoods compared to the population of higher socioeconomic status (Chugh et al. 2004). Patients under the age of 65 years were found to have a steeper socioeconomic gradient than those over the age of 65 years. Risk factors for cardiac disease and SCD, such as smoking, hypercholesterolemia, obesity, lack of physical activity, and diabetes, were also found to be higher among low socioeconomic status populations (Mensah et al. 2005; Rozanski et al. 2005). A higher incidence of out-of-hospital death in lower socioeconomic status population has been reported (Soo et al. 2001). Emotions and behavior also affect human health, and poor emotions or behaviors can have an adverse effect on health. It was suggested that psychosocial factors and stressful activities also play a contributory role in the etiology of SCD (Steptoe and Kivimaki 2013).

High alcohol consumption ( $>5$ drinks/day) is associated with an increased risk of ventricular arrhythmia and SCD. Contrary, consumption of light-to-moderate amounts of alcohol (2 to 6 drinks/week) correlated with significantly reduced risk of SCD (Albert et al. 1999). Cocaine can also contribute to sudden cardiac death due to its pro-arrhythmic effect (Billman 1990). Recently the possible relationship between chronic heavy smoking and increased risk for SCD has been proposed. Smoking is associated with prolonged Tp-e interval, increased Tp-e/QT ratio, and Tp-e/QTc ratio (Ilgenli et al. 2015).

Cyclo-oxygenase-2 (COX2) selective NSAIDs are preferred over non-selective NSAIDs. A 5-fold difference in incidence of acute MI was found between patients treated with rofecoxib $50 \mathrm{mg} /$ day and naproxen $1000 \mathrm{mg} /$ day (Bombardier et al. 2000). A metaanalysis of clinical trials of celecoxib and rofecoxib (Mukherjee et al. 2001) showed similar results. Graham et al. (Graham et al. 2005) suggest that the risk of serious coronary heart 
disease increased with use of rofecoxib as compared to use with celecoxib, and that naproxen does not protect against serious coronary artery disease.

Antipsychotic medications, like phenothiazine and haloperidol, can also increase risk for SCD (Laposata et al. 1988; Suessbrich et al. 1997). The risk for SCD with butyrophenone antipsychotic was found to be highest in recent users, but it remained elevated with prolonged use (Straus et al. 2004). In a cohort study of 1,487 patients, it was proposed that SSRIs and TCAs in doses of $<100 \mathrm{mg}$, have no association with SCD, but a higher dose of TCAs was associated with increased relative risk of SCD (Ray et al. 2004). Atypical antipsychotics increase the risk of SCD (Ray et al. 2009).

Cardiac QTc-prolonging drugs are a risk factor for fatal arrhythmias. However, Straus et al. (Straus et al. 2005) suggested that non-cardiac QTc-prolonging drugs also increase the risk of SCD. Drugs such as erythromycin, clarithromycin, cisapride, domperidone, chlorpromazine, haloperidol, pimozide, and thioridazine were studied along with inclusion of co-variates associated with increased risk of SCD like arrhythmia, heart failure, diabetes mellitus, hypertension, hypercholesterolemia, smoking, alcohol abuse, and cerebrovascular and cardiovascular ischemia. An almost 3-fold increased risk of sudden cardiac death was noted with the current use of non-cardiac QTc-prolonging drugs, in contrary to the assumption in the past that use of non-cardiac QTc-prolonging drugs was not associated with an increased risk for SCD. The risk was significantly increased with gastro-intestinal and antipsychotic medication. Drug-induced prolongation of the QTc interval, Torsades de Pointes, and ventricular arrhythmias are associated with use of cisapride and more predominantly with the concurrent use of inhibitors of cytochrome P450 CYP3A4, like itraconazole, ketoconazole, or macrolides. 


\section{Triggers of SCD}

Emotional stress, physical over-activity and vigorous activity in a person having coronary artery disease can precipitate SCD due to ischemia (Albert et al. 2000; Reddy et al. 2009) (Figure 4). Regular exercise is associated with long-term reduction in SCD risk (Haskell et al. 2007; Manson et al. 1999). However, the British Regional Heart Study found significant reduction in SCD risk with both moderate and vigorous exercise (Wannamethee et al. 1995). Many retrospective and cross-sectional studies have suggested the association of vigorous exercise or activity with SCD but a prospective study (Albert et al. 2000) showed that transient bouts of vigorous activity are associated with increased SCD risk, and habitual vigorous exercise can diminish the risk of SCD during vigorous activity. Electrolyte imbalance, mainly potassium, can trigger SCD. However, the largest percentage of correlation of SCD with exercise is with light activities indicating the importance of education and awareness about symptoms and signs of SCD (Figure 4). Hence, even the smallest indication of chest pain should never be overlooked (Reddy et al. 2009).

\section{Sudden cardiac deaths in apparently normal heart}

$\mathrm{CAD}$, previous $\mathrm{MI}$, heart failure with decreased $\mathrm{EF}$, and ventricular arrhythmias are the known risk factors for SCD. However, SCD can also occur in persons with normal hearts. The estimated incidence rate of SCD in infants, children, adolescents, and young adults is about 1.3 to 8.5 per 100,000 patient/years (Liberthson 1996) and claims thousands of lives per year. Among athletes, SCD may be due to hypertrophic cardiomyopathy, abnormal blood circulation, and increased cardiac mass caused by cardiomyopathy (Maron et al. 1996). The most common causes of SCD in young athletes are hypertrophic cardiomyopathy and congenital coronary artery anomaly; less common causes are myocarditis, aortic rupture (Marfan syndrome), and mitral valve prolapse, while arrhythmogenic right ventricular 
cardiomyopathy, atherosclerosis, coronary artery disease, aortic valve stenosis, and conducting system anomalies are uncommon causes (Corrado et al. 2005). Though the incidence rate seems lower, there are thousands of deaths per year in young athletes. Preparticipation screening and cardiovascular evaluation were recommended and a protocol was established to be followed for screening consisting of family history, physical examination, and 12-lead EKG as the primary recommendation, with echo, stress test, 24-hour Holter monitoring, cardiac MRI, angio/endomyocardial biopsy (EMB) and electrophysiological studies (EPS) in clinical cases with findings on primary examination (Corrado et al. 2005) (Figure 1).

Patients suffering from SCD with normal hearts or without a history of cardiac disease, on autopsy showed structural abnormalities as the major cause of death (Chugh et al. 2000), suggesting the need for increased awareness among the general population, primary care physicians, pathologists, and radiologists, as well as better screening programs to diagnose these undetected and undiagnosed heart issues (Papadakis et al. 2009). Sudden unexplained deaths are also a major concern in SCD epidemiology, and careful post-mortem and histological examination can play a vital role (Huikuri et al. 2001). However, the lack of details of the heart weight/ wall thickness or the evidence of fibrosis leads to vague estimation and conclusion, as post-mortems is often not performed by the cardiac pathologists. The autopsy studies are also influenced by vague histories, insufficient or lack of autopsy findings, and lack of supporting ancillary testing. To avoid these concerns, there is a need of standardized approach on the decision making in autopsy of SCD cases. The guidelines for an adequate assessment of the SCD should include a standard protocol for heart examination as well as histological sampling, toxicology and molecular investigations to detect the infarction and fibrosis, and the involvement of a cardiovascular pathologist to 
improve the accuracy. Autopsy should include examining every subsystem of the heart (pericardium, pericardial cavity, myocardium, cardiac valves and conducting system) and vessels (coronary arteries, pulmonary arteries and veins, aorta and venae cavae) (Harmon et al. 2015; Yang et al. 2008). Further, the use of post-mortem imaging (post-mortem multidetector computed tomography and cardiac 3T magnetic resonance imaging) may help in visualizing the myocardial areas of chronic, sub-acute or acute myocardial infarction in situ, as well as in peracute infarction normally not visible on autopsy (Jackowski et al. 2013; Michaud et al. 2014; Schmidt 2013) (Figure 1).

\section{Predictive factors and risk stratification: The need of time}

SCD accounts for nearly 250,000-350,000 deaths per year (Birati et al. 2016; Chugh et al. 2004). To have an impact upon this public health burden, there is a need to develop risk profiling strategies that can distinguish high-risk patients from those with low-risk within the general population (Fishman et al. 2010). Currently, the presence of CAD, genetic disease that makes someone prone to $\mathrm{SCD}$, or $\mathrm{EF} \leq 30 \%-35 \%$ are used as the criteria for preventive therapy and ICD trials. Patients' medical and familial history, the Framingham criteria, clinical markers for the presence of CAD, electrophysiological components (PR interval, QT interval, QTC), heart rate variability, BNP, chronic renal disease, and T-wave alternans and repolarization-related predictors are used for risk stratification, but these criteria are not sufficient in finding and preventing SCD events. Dietary markers, such as long-chain fatty acids; magnesium; non-esterified fatty acids; trans-fatty acids; inflammatory markers such as interleukin-6, fibrinogen, and C-reactive protein; metabolic markers such as aldosterone, cystatin $\mathrm{C}$, renin, vitamin $\mathrm{D}$, and parathyroid hormone; and neurohormonal markers like brain natriuretic peptide (BNP) and amino-terminal pro-B type natriuretic peptide (NT-pro-BNP) have been studied in correlation with SCD (Deo and Albert 2012). These studies indicate the need to find improved clinical and non-clinical predictors for a better risk stratification. 
The presence of severe left ventricular heart failure is a strong predictor for SCD and makes it a factor for primary prevention through ICD. However, only $20 \%-30 \%$ of patients with ICD; receive appropriate therapies for a follow-up period of $4-5$ years (Bardy et al. 2005; Moss et al. 2002;). Further, not all patients who have SCD have severe LV failure; some have normal LV function and some have mild-to-moderate LV failure. Recently, it has been proposed that neurohumoral imaging with ${ }^{123}$ I-metaidobenzyl-guanidine can predict SCD independently of EF. This could be a new marker for risk stratification (Kasama et al. 2015).

Microvolt T-wave alternans (MTWA) is a recent parameter of interest for risk stratification. Changing beat to beat electrical amplitude is called pulsus alternans or electrical alternans and fluctuation in amplitude of T-wave is called T-wave alternans. Electrical alternans has been linked with ventricular arrhythmia and SCD. However, technical difficulties have limited its use in clinical diagnosis. It recently has been suggested that analysis of heart activity reflected by multimodal signals gives a more comprehensive estimate. Further ECG features, thoracic signals, and beat-to-beat variability of heart rate should collectively be analyzed for estimating repolarization alternans and clinical outcome (Krisciukaitis et al. 2014). T-wave alternans can be a predictor of arrhythmias and SCD (Chow et al. 2006). Low mortality rates have been reported in MTWA-negative patients (Armoundas et al. 2005; Hohnloser et al. 2009), and the presence of MTWA predicts an approximately 4-fold increased risk for ventricular arrhythmia (Gehi et al. 2005), with a predictive value of 99.6 (Ikeda et al. 2006). However, another study suggests that the risk of ventricular tachycardia does not differ according to the MTWA classification (Chow et al. 2008).

In the Atherosclerosis Risk in Communities (ARIC) study for repolarization related predictors, it was found that the spatial angle between Tpeak and normal repolarization 
reference vector $[\Theta(\mathrm{Tp} \mid$ Tref $)]$ in men and Tonset and Tpeak vector magnitude ratio $[\mathrm{ToV} / \mathrm{TpV}]$ in women are the strongest independent predictors for SCD (Rautaharju et al. 2015). However, the limited predictive power of common arrhythmia risk variables particularly the autonomic and standard ECG markers, in identifying the patient at risk of SCD was suggested in a study including 700 patients with acute MI on $\beta$-blocker therapy, after considering the risk variables like EF, baroreflex sensitivity, non-sustained VT, ventricular premature beats, QT interval, QRS duration and signal-averaged ECG. It was proposed that co-morbid conditions like diabetes and NYHA functional status also influence the results and that arrhythmic event or SCDs did not concentrate near the index event, but may occur more than 18 months after acute MI (Huikuri et al. 2003).

Recently it has been suggested that CHADS2 scoring (scoring to evaluate the risk of cerebral infarction in AF patients, with 1 point each for age, presence of hypertension, diabetes mellitus, and history of heart failure, and 2 points for history of stroke and transient ischemic attack) can be used to predict coronary atherosclerosis on CT and can be correlated with prognosis (Uehara et al. 2015). Since coronary artery disease is the main risk factor for $\mathrm{SCD}$, a thought should be given to using CHADS2 for risk stratification in at-risk SCD patients. The time interval from the peak to the end of the $\mathrm{T}$ wave (Tp-e) is another predictor for SCD in patients with long QT syndrome, Brugada syndrome, structural heart disease, and hypertrophic cardiomyopathy (Yagishita et al. 2014). Measurement of exercise cardiac power, a ratio of directly measured maximal oxygen uptake with peak systolic blood pressure during exercise, can be used as a non-invasive measure for risk stratification (Kurl et al. 2015). 


\section{Prevention and treatment}

Coronary artery bypass surgery, percutaneous angioplasty-stent, aspirin use, cholesterol-lowering therapies, and increased awareness of coronary artery disease prevention are the main strategies for the prevention of SCD (Chugh et al. 2008). The main etiology behind coronary artery ischemia is plaque rupture, so methods to prevent plaque rupture, plaque stabilization, decreasing plaque formation and searching risk markers for sudden plaque rupture should be researched. The role of cholesterol in plaque formation and SCD has been studied, with some suggesting its significant role (Thorgeirsson et al. 2005) while others do not (Albert et al. 2003). Low-density lipoprotein (LDL) plays a significant role in atheroma formation and atherosclerosis, causing plaque formation (Falk 2006), but studies found no significant relationship between total cholesterol and LDL for plaque formation, however it was found that LDL is a significant risk factor and predictor of SCD in the short term $(<2 \mathrm{yr})$ but not for the long term ( $>2 \mathrm{ys})$ (Benchimol et al. 2000). Preventing acute ischemia due to plaque rupture using strategies involving plaque stabilization is an evolving area of research (Jia et al. 2006: Rai et al. 2016; Rao et al. 2014; Rao et al. 2015; Rao et al. 2016) (Figure 1).

Since arrhythmias are the major precipitating factors of SCD, treating arrhythmias is beneficial. Acute unstable arrhythmias should be treated with an external defibrillator according to the ACLS algorithm; it has been suggested that biphasic waveform defibrillation is more effective than monophasic defibrillation (Morrison et al. 2005). Treating the patient's arrhythmia in the hospital is a secondary prevention, but the proportion of out-of-hospital death is higher, so there is a need to focus on primary, not secondary prevention. Holter monitoring may play a role: the prediction of sudden cardiac death and low incidence of SCD has been reported with Holter monitoring in patients with preserved left ventricular function (Makikallio et al. 2005). Recently, the presence of a wide and/or large S-wave in lead I in 
Brugada syndrome has been reported as a powerful electrocardiographic predictor of lifethreatening ventricular arrhythmias (Calo et al. 2016). Cardiac arrhythmias during hemodialysis are an important contributor to cardiac mortality or sudden death, and the use of an implantable loop recorder in monitoring in a dialysis study has been suggested as a novel way to decrease the incidence of sudden death by understanding the nature of arrhythmias (Charytan et al. 2016). Similarly the role of increased C-reactive protein, electrocardiographic Q-wave, and impaired myocardial fatty acid metabolism has been discussed as a non-invasive strategy to identify at-risk patients before dialysis (Nakata et al. 2015).

Hypertrophic cardiomyopathy is a major cause of SCD in the adult population and young athletes, and it has been suggested that intracellular calcium handling in the heart is altered before development of $\mathrm{LVH}$; in addition progression of $\mathrm{LVH}$ development can be attenuated by preclinical use of diltiazem (Ho et al. 2015). Sudden cardiac death in heart failure with reduced EF has been well-studied, and the potential role of implantable devices and pharmacological agents to prevent SCD in heart failure patients with preserved EF have been reported (Vaduganathan et al. 2016). However, recently deaths with EF $>35 \%$ has been documented in a retrospective study involving orthotropic heart transplant patients, suggesting that reduced EF was not associated with SCD (Birati et al. 2016). Further, the lower predicted mortality risk in patients with $\mathrm{EF}<30 \%$ but no other risk factor compared to higher mortality and higher risk of SCD in patients with $\mathrm{EF}>30 \%$ with other risk factors, suggests that the risk of SCD in CAD patients depends not only on EF but also on other risk factors. Hence, other risk factors as well as predictive risk stratifiers (QRS duration, ventricular ectopy, signal-averaged electrocardiogram, microvolt T-wave alternans, markers of autonomic tone and programmed ventricular stimulation) should be taken into consideration along with EF during risk stratification (Buxton et al. 2007; Dagres and Hindricks 2013) (Figure 1). 
Clinical trials for the primary and secondary prevention of SCD indicate that no single agent is sufficient for prevention or treatment. Beta-blockers reduce the risk for arrhythmia and SCD, anti-arrhythmic drugs increase the relative risk for SCD, fish oil and statins reduce the relative risk for arrhythmia, but there were limitations with all these studies (Table 2). In some of these trials, it was found that ICDs are beneficial for primary and secondary prevention as well as for reduction in mortality. The time of use of ICDs in a patient with acute MI is vital, but some trials showed that there is no difference in overall survival (Table 2). The potential biases in the study designs of ICDs can be epidemiological or economic, selection, or due to the predefined end-point of the study, concomitant treatment, publication and differences in trial follow-up (Huikuri et al. 2003). It was also reported that ICD can be implanted intra-pericardially in young children, but with a high risk of SCD (Kwon et al. 2012).

Channelopathy due to mutations is an important etiology of SCD and post-mortem genetic testing (Anderson et al. 2016; Cann et al. 2016), molecular screening (Kauferstein et al. 2013), and next-generation sequencing (Campuzano et al. 2014; Hertz et al. 2015; Millet et al. 2014). Whole exome sequencing may be a promising, time- and cost- effective technique for discovering the genetic basis of SCD in at-risk families and patients (Bagnall et al. 2014; Hajj et al. 2014; Narula et al. 2015). Genetic mapping of at-risk families with a history of SCD or cardiomyopathy may also be used to predict the risk (Bulbanat et al. 2014). The use of in silico tools (SIFT, PolyPhen-2, PROVEAN, SNPs \& GO and SNAP), and metaservers (Meta-SNP and PredictSNP) in assessing the variants in the KCNQ1, KCNH2 and SCN5A genes have been discussed (Leong et al. 2015) and may be of use in risk stratification. Similarly, genome-wide association studies have reported many gene loci associated with familial and sporadic atrial fibrillation and may be useful in risk stratification (Chen et al. 2015). 
Screening patients for G643S-polymorphism before prescribing psychotropic drugs also may reduce the risk for SCD (Kamei et al. 2014). The association of c. 5570T>A missense mutation in the ANK2 gene with second-degree atrio-ventricular block using nextgeneration sequencing further supports the need for risk identification (Asadi et al. 2016). Similarly, identification of pathogenic mutations associated with inherited cardiomyopathy by the Ion Torrent-PGM system for gene sequencing may be used for risk assessment of SCD (Zhao et al. 2016). These modalities also may help in forensic analysis by differentiating SCD from other causes of sudden unexplained death, identifying the pathogenic variants responsible for $\mathrm{SCD}$, and in treatment guidelines for at-risk individuals, as drugs which can precipitate arrhythmia can be avoided. Additionally these tests also suggested a role of genetic polymorphism in SCD, and indicate that special attention should be paid to symptomatic patients and aids in prognosis for diagnosed patients (Uzieblo-Zyczkowska et al. 2014).

Though SCD accounts for about $>60 \%$ of cardiac disease-related deaths, the major concerns are an increasing proportion of cases that never make it to the hospital, aging U.S. population, late onset of fatal cardiac events, and an increasing proportion of out-of-hospital deaths (Zheng et al. 2001). To decrease SCD mortality, the main issues to monitor and improve are education about symptoms and signs, better primary and secondary prevention, and better emergency cardiac care in reach. The other issue of concern is the proportion of out-of-hospital cardiac-related death, mainly in women. Due to the presence of atypical symptoms of chest pain for cardiac disease in women, such as jaw pain, shoulder pain, nausea, abdominal or epigastric pain, and back pain, there are chances that ongoing events go unrecognized and receive less aggressive and delayed treatment leading to the higher death rate in young women (Roger et al. 2000). 
It is evident that a majority of victims remain hidden within the larger, low-risk population, so there is a need for further research to find a highly powered prognostic indicator and a better preventive treatment modality for better outcome of the cardiac event. Since arrhythmias (due to arrhythmia syndrome, cardiomyopathies, genetic diseases etc.) are the precipitating events for SCD, a national registry system for the patients with SCD family history, or diagnosed as at risk patient for SCD, as well as the ongoing researches on SCD and their outcome, similar to GENCOR may help in decreasing the incidence and a better risk stratification strategy (Hermans et al. 2006). There is also a need to increase awareness about the SCD risk factors, sign and symptoms, etiology and outcome, and the necessity to discuss the issue with primary care physicians. The lower incidence of SCD among US firefighter compared to general population has been attributed to the healthy life style and practices, suggesting the need of increasing awareness in general population (Farioli et al. 2015). Recently, body mass index as a predictor of SCD and use of ECG abnormalities in at-risk patients have been discussed (Eranti et al. 2015) (Figure 1).

\section{Conclusion}

Though the annual incidence rate of SCD is 300-350,000 in the United States and around 4-5 million for the rest of the world, the declining rate of mortality in the United States due to coronary artery disease indicates the improvement and efficacy of emergency resuscitation and treatment. Life-style modifications; dietary modifications; mild daily physical activity; effective treatment of hypercholesterolemia, hypertension, and diabetes; and nut and fish oil consumption can decrease the incidence of coronary artery disease. Treatment with aspirin and coronary interventions, such as angioplasty and ICDs, can decrease the prevalence of sudden cardiac arrest and SCD. Counseling patients and family members is another important way to decrease the SCD incidence. However, better risk stratification strategies by conducting community-based studies, retrospective studies, and prospective studies are 
needed. Identifying novel markers for SCD, early markers for plaque rupture to prevent acute ischemia may play an important role. The study of genetics and involved genes that cause congenital cardiac diseases and precipitate SCD, via gene mapping or gene signature, and the development of gene markers for SCD, can help us to understand and treat the disease through genomic medicine or gene therapy (Fishman et al. 2010; Mozaffarian et al. 2015).

Despite the progress in the field of prediction and prevention of SCD from various research studies and clinical trials, there still is a need for adequately designed studies for reliable testing of various known risk variables with clinical utility for the prediction of sudden cardiac death. There is a need to consider the conventional risk factors along with other potential factors that cause fatal arrhythmia and sudden cardiac death. Difficulty in identifying the individual at higher risk for $\mathrm{SCD}$, difficulty in recognizing and defining $\mathrm{SCD}$, overestimation of SCD due to unknown cardiac rhythm during presentation, and the insufficient and limited predictive power of various indicators or variables for the prevalence of SCD indicate that ongoing research is needed.

\section{Acknowledgement}

This work was supported by research grants R01 HL112597, R01 HL116042, and R01 HL120659 to DK Agrawal from the National Heart, Lung and Blood Institute, National Institutes of Health, USA. The content of this review article is solely the responsibility of the authors and does not necessarily represent the official views of the National Institutes of Health.

\section{Financial and competing interests' disclosure}

The authors have no other relevant affiliations or financial involvement with any organization or entity with financial interest or financial conflict with the subject matter or materials 
discussed in the manuscript apart from those disclosed. No writing assistance was utilized in the production of this manuscript.

\section{References}

Akilzhanova, A., Guelly, C., Nuralinov, O., Nurkina, Z., Nazhat, D., Smagulov, S., Tursunbekov, A., Alzhanova, A., Rashbayeva, G., Abdrakhmanov, A., Dosmagambet, S., et al. 2014. RYR2 Sequencing Reveals Novel Missense Mutations in a Kazakh Idiopathic Ventricular Tachycardia Study Cohort. PloS One, 9(6): e101059. doi: 10.1371/journal.pone.0101059

Aksakal, A., Arslan, U., Yaman, M., Urumdaş, M., and Ateş, A. H. 2014. Spontaneous coronary artery dissection as a cause of myocardial infarction. World J. Cardiol. 6(12): 1290-1292. doi: 10.4330/wjc.v6.i12.1290.

Albert, C. M., Chae, C. U., Grodstein, F., Rose, L. M., Rexrode, K. M., Ruskin, J. N., Stampfer, M. J., and Manson, J. E. 2003. Prospective study of sudden cardiac death among women in the United States. Circulation, 107(16): 2096-2101. DOI: 10.1161/01.CIR.0000065223.21530.11

Albert, C. M., Manson, J. E., Cook, N. R., Ajani, U. A., Gaziano, J. M., and Hennekens, C. H. 1999. Moderate alcohol consumption and the risk of sudden cardiac death among US male physicians. Circulation, 100(9): 944-950.

Albert, C. M., Mittleman, M. A., Chae, C. U., Lee, I. M., Hennekens, C. H., and Manson, J. E. 2000. Triggering of sudden death from cardiac causes by vigorous exertion. N. Engl. J. Med. 343(19): 1355-1361. DOI: 10.1056/NEJM200011093431902

Anderson, J. H., Tester, D. J., Will, M. L., and Ackerman, M. J. 2016. Whole Exome Molecular Autopsy Following Exertion-Related Sudden Unexplained Death in the Young. Circ. Cardiovasc. Genet. 9(3):259-65 doi:

10.1161/CIRCGENETICS.115.001370 
Antzelevitch, C., Pollevick, G. D., Cordeiro, J. M., Casis, O., Sanguinetti, M. C., Aizawa, Y., Guerchicoff, A., Pfeiffer, R., Oliva, A., Wollnik, B., et al. 2007. Loss-of-function mutations in the cardiac calcium channel underlie a new clinical entity characterized by ST-segment elevation, short QT intervals, and sudden cardiac death. Circulation, 115(4): 442-449. DOI: 10.1161/CIRCULATIONAHA.106.668392

Arakawa, J., Hamabe, A., Aiba, T., Nagai, T., Yoshida, M., Touya, T., Ishigami, N., Hisadome, H., Katsushika, S., Tabata, H., Miyamoto, Y., and Shimizu, W. 2015. A novel cardiac ryanodine receptor gene (RyR2) mutation in an athlete with aborted sudden cardiac death: a case of adult-onset catecholaminergic polymorphic ventricular tachycardia. Heart Vessels, 30(6):835-40. doi: 10.1007/s00380-014-0555$\mathrm{y}$

Arking, D. E., Chugh, S. S., Chakravarti, A., and Spooner, P. M. 2004. Genomics in sudden cardiac death. Circ. Res. 94(6): 712-723. DOI:

10.1161/01.RES.0000123861.16082.95

Armoundas, A. A., Hohnloser, S.H., Ikeda, T., and Cohen, R. J. 2005. Can microvolt T-wave alternans testing reduce unnecessary defibrillator implantation? Nat. Clin. Pract. Cardiovasc. Med. 2(10): 522-528. DOI: 10.1038/ncpcardio0323

Asadi, M., Foo, R., Samienasab, M. R., Salehi, A. R., Kheirollahi, M., Khanahmad, H., and Salehi, R. 2016. Genetic analysis of Iranian family with hereditary cardiac arrhythmias by next generation sequencing. Adv. Biomed. Res. 5: 55. doi: $10.4103 / 2277-9175.178801$

Bansch, D., Antz, M., Boczor, S., Volkmer, M., Tebbenjohanns, J., Seidl, K., Block, M., Gietzen, F., Berger, J., and Kuck, K. H. 2002. Primary prevention of sudden cardiac death in idiopathic dilated cardiomyopathy the Cardiomyopathy Trial (CAT). Circulation, 105(12): 1453-1458. 
Bagnall, R. D., Molloy, L. K., Kalman, J. M., and Semsarian, C. 2014. Exome sequencing identifies a mutation in the ACTN2 gene in a family with idiopathic ventricular fibrillation, left ventricular noncompaction, and sudden death. BMC Med. Genet. 15(1): 99. doi: 10.1186/s12881-014-0099-0

Bardy, G. H., Lee, K. L., Mark, D. B., Poole, J. E., Packer, D. L., Boineau, R., Domanski, M., Troutman, C., Anderson, J., et al. 2005. Amiodarone or an implantable cardioverterdefibrillator for congestive heart failure. N. Engl. J. Med. 352(3): 225-237. DOI: 10.1056/NEJMoa043399

Benchimol, D., Dubroca, B., Bernard, V., Lavie, J., Paviot, B., Benchimol, H., Couffinhal, T., Pillois, X., Dartigues, J., and Bonnet, J. 2000. Short-and long-term risk factors for sudden death in patients with stable angina. Int. J. Cardiol. 76(2): 147-156. doi.10.1016/S0167-5273(00)00370-3

Billman, G. E. 1990. Mechanisms responsible for the cardiotoxic effects of cocaine. FASEB J. 4(8): 2469-2475.

Birati, E. Y., Mathelier, H., Molina, M., Hanff, T. C., Mazurek, J. A., Atluri, P. et al. 2016. Comparison of Causes of Death After Heart Transplantation in Patients With Left Ventricular Ejection Fractions $\leq 35 \%$ Versus $>35$. Am. J. Cardiol. 117(8):1322-6. doi: 10.1016/j.amjcard.2016.01.028

Bombardier, C., Laine, L., Reicin, A., Shapiro, D., Burgos-Vargas, R., Davis, B., Day, R., Ferraz, M. B., Hawkey, C. J., Hochberg, M. C., Kvien, T. K., and Schnitzer, T. J.; VIGOR Study Group. 2000. Comparison of upper gastrointestinal toxicity of rofecoxib and naproxen in patients with rheumatoid arthritis. N. Engl. J. Med. 343(21): 1520-1528. DOI: 10.1056/NEJM200011233432103 
Bourdin, B., Tétreault, M. P., Sauvé, R., Lesage, S., and Parent, L. 2014. Functional characterization of $\mathrm{CaV} \alpha 2 \delta$ mutations associated with sudden cardiac death. J. Biol. Chem. 290(5):2854-69. doi: 10.1074/jbc.M114.597930

Bulbanat, B., Antony, D., Behbehani, K., Alsmadi, O., Thomas, D., and Kamkar, M. M. 2014. Sudden cardiac death diagnosed with dilated cardiomyopathy in a Kuwaiti family: a case report. BMC Research Notes, 7(1): 914. doi: 10.1186/1756-0500-7-914

Burke, A., Creighton, W., Mont, E., Li, L., Hogan, S., Kutys, R., Fowler, D., and Virmani, R. 2005. Role of SCN5A Y1102 polymorphism in sudden cardiac death in blacks. Circulation, 112(6): 798-802. DOI: 10.1161/CIRCULATIONAHA.104.482760

Burke, A. P., Farb, A., Malcom, G. T., Liang, Y., Smialek, J., and Virmani, R. 1998. Effect of risk factors on the mechanism of acute thrombosis and sudden coronary death in women. Circulation, 97(21): 2110-2116. doi. 10.1161/01.CIR.97.21.2110

Buxton, A. E., Lee, K. L., Hafley, G. E., Pires, L. A., Fisher, J. D., Gold, M. R., et al. 2007 Limitations of ejection fraction for prediction of sudden death risk in patients with coronary artery disease: lessons from the MUSTT study. J. Am. Coll. Cardiol. 50(12):1150-7. DOI: 10.1016/j.jacc.2007.04.095

Byrne, R., Constant, O., Smyth, Y., Callagy, G., Nash, P., Daly, K., and Crowley, J. 2008. Multiple source surveillance incidence and aetiology of out-of-hospital sudden cardiac death in a rural population in the West of Ireland. Eur. Heart J. 29(11):141823. doi: 10.1093/eurheartj/ehn155

Calo, L., Giustetto, C., Martino, A., Sciarra, L., Cerrato, N., Marziali, M., Rauzino, J., Carlino, G., de Ruvo, E., and Guerra, F. 2016. A New Electrocardiographic Marker of Sudden Death in Brugada Syndrome: The S-Wave in Lead I. J. Am. Coll. Cardiol. 67(12): 1427-1440. doi: 10.1016/j.jacc.2016.01.024 
Campuzano, O., Sanchez-Molero, O., Mademont-Soler, I., Riuró, H., Allegue, C., Coll, M., Pérez-Serra, A., Mates, J., Picó, F., Iglesias, A., and Brugada, R. 2015. Rare Titin (TTN) Variants in Diseases Associated with Sudden Cardiac Death. Int. J. Mol. Sci. 16(10): 25773-25787. doi: 10.3390/ijms161025773.

Campuzano, O., Sarquella-Brugada, G., Mademont-Soler, I., Allegue, C., Cesar, S., FerrerCosta, C., Coll, M., Mates, J., Iglesias, A., Brugada, J., and Brugada, R. 2014 Identification of Genetic Alterations, as Causative Genetic Defects in Long QT Syndrome, Using Next Generation Sequencing Technology. PloS One, 9(12): e114894. doi: 10.1371/journal.pone.0114894.

Cann, F., Corbett, M., O'Sullivan, D., Tennant, S., Hailey, H., Grieve, J. H., Broadhurst, P., Rankin, R., and Dean, J. C. 2016. Phenotype Driven Molecular Autopsy for Sudden Cardiac Death. Clin. Genet. doi: 10.1111/cge.12778

Charytan, D. M., Foley, R., McCullough, P. A., Rogers, J. D., Zimetbaum, P., Herzog, C. A., and Tumlin, J. A.; MiD Investigators and Committees. 2016. Arrhythmia and Sudden Death in Hemodialysis Patients: Protocol and Baseline Characteristics of the Monitoring in Dialysis Study. Clin. J. Am. Soc. Nephrol. 11(4):721-34. doi: 10.2215/CJN.09350915.

Chen, L. Y., Ballew, J. D., Herron, K. J., Rodeheffer, R. J., and Olson, T. M. 2007. A common polymorphism in SCN5A is associated with lone atrial fibrillation. Clin. Pharmacol. Ther. 81(1): 35-41. DOI: 10.1038/sj.clpt.6100016

Chen, S., Wang, C., Wang, X., Xu, C., Wu, M., Wang, P., Tu, X., and Wang, Q. K. 2015. Significant Association Between CAV1 Variant rs3807989 on 7p31 and Atrial Fibrillation in a Chinese Han Population. J. Am. Heart Assoc. 4(5): e001980. doi: 10.1161/JAHA.115.001980. 
Chen, Z. M., Pan, H. C., Chen, Y. P., Peto, R., Collins, R., Jiang, L. X., Xie, J. X., and Liu, L. S.; COMMIT (ClOpidogrel and Metoprolol in Myocardial Infarction Trial) collaborative group. 2005. Early intravenous then oral metoprolol in 45,852 patients with acute myocardial infarction: randomised placebo-controlled trial. Lancet, 366(9497): 1622-1632. DOI: 10.1016/S0140-6736(05)67661-1

Cheng, J., Van Norstrand, D. W., Medeiros-Domingo, A., Valdivia, C., Tan, B. H., Ye, B., Kroboth, S., Vatta, M., Tester, D. J., January, C. T., Makielski, J. C., and Ackerman, M. J. 2009. Alpha1-Syntrophin mutations identified in sudden infant death syndrome cause an increase in late cardiac sodium current. Circ. Arrhythm. Electrophysiol. 2(6): 667-676. doi: 10.1161/CIRCEP.109.891440.

Chockalingam, P., Clur, S. A., Breur, J. M., Kriebel, T., Paul, T., Rammeloo, L. A., Wilde, A. A., and Blom, N. A. 2012. The diagnostic and therapeutic aspects of loss-offunction cardiac sodium channelopathies in children. Heart Rhythm, 9(12): 19861992. doi: 10.1016/j.hrthm.2012.08.011

Chow, T., Kereiakes, D. J., Bartone, C., Booth. T., Schloss, E. J., Waller, T., Chung, E. S., Menon, S., Nallamothu, B. K., and Chan, P. S. 2006. Prognostic utility of microvolt T-wave alternans in risk stratification of patients with ischemic cardiomyopathy. J. Am. Coll. Cardiol. 47(9): 1820-1827. DOI: 10.1016/j.jacc.2005.11.079

Chow, T., Kereiakes, D. J., Onufer, J., Woelfel, A., Gursoy, S., Peterson, B. J., Brown, M. L., Pu, W., and Benditt, D. G.; MASTER Trial Investigators. 2008. Does microvolt Twave alternans testing predict ventricular tachyarrhythmias in patients with ischemic cardiomyopathy and prophylactic defibrillators? The MASTER (Microvolt T Wave Alternans Testing for Risk Stratification of Post-Myocardial Infarction Patients) trial. J. Am. Coll. Cardiol. 52(20): 1607-1615. doi: 10.1016/j.jacc.2008.08.018. 
Christiansen, M., Hedley, P.L., Theilade, J., Stoevring, B., Leren, T. P., Eschen, O., Sørensen, K. M., Tybjærg-Hansen, A., Ousager, L. B., Pedersen, L. N., et al. 2014. Mutations in Danish patients with long QT syndrome and the identification of a large founder family with p. F29L in KCNH2. BMC Med. Genet. 15(1):31. doi: $10.1186 / 1471-2350-15-31$.

Chugh, S. S., Jui, J., Gunson, K., Stecker, E. C., John, B. T., Thompson, B., Ilias, N., Vickers, C., Dogra, V., Daya, M., Kron, J., Zheng, Z. J., Mensah, G., and McAnulty, J. 2004. Current burden of sudden cardiac death: multiple source surveillance versus retrospective death certificate-based review in a large US community. J. Am. Coll. Cardiol 44(6): 1268-1275. DOI: 10.1016/j.jacc.2004.06.029

Chugh, S. S., Kelly, K. L., and Titus, J. L. 2000. Sudden cardiac death with apparently normal heart. Circulation, 102(6): 649-654. doi.10.1161/01.CIR.102.6.649

Chugh, S. S., Reinier, K., Teodorescu, C., Evanado, A., Kehr, E., Al Samara, M., Mariani, R., Gunson, K., and Jui, J. 2008. Epidemiology of sudden cardiac death: clinical and research implications. Prog. Cardiovasc. Dis. 51(3): 213-228. doi: 10.1016/j.pcad.2008.06.003.

Corrado, D., Pelliccia, A., Bjørnstad, H. H., Vanhees, L., Biffi, A., Borjesson, M., Panhuyzen-Goedkoop, N., Deligiannis, A., Solberg, E., Dugmore, D., et al. 2005. Cardiovascular pre-participation screening of young competitive athletes for prevention of sudden death: proposal for a common European protocol Consensus Statement of the Study Group of Sport Cardiology of the Working Group of Cardiac Rehabilitation and Exercise Physiology and the Working Group of Myocardial and Pericardial Diseases of the European Society of Cardiology. Eur. Heart J. 26(5): 516524. DOI: 10.1093/eurheartj/ehi108 
Dagres, N. and Hindricks, G. 2013. Risk stratification after myocardial infarction: is left ventricular ejection fraction enough to prevent sudden cardiac death? Eur. Heart J. 34(26):1964-71 doi: 10.1093/eurheartj/eht109

de Luna, A. B., Coumel, P., and Leclercq, J. F. 1989. Ambulatory sudden cardiac death: mechanisms of production of fatal arrhythmia on the basis of data from 157 cases. Am. Heart J. 117(1): 151-159. PMID: 2911968

Deo, R., and Albert, C. M. 2012. Epidemiology and genetics of sudden cardiac death. Circulation, 125(4): 620-637. doi: 10.1161/CIRCULATIONAHA.111.023838.

Desai, A. S., Fang, J. C., Maisel, W. H., and Baughman, K. L. 2004. Implantable defibrillators for the prevention of mortality in patients with nonischemic cardiomyopathy: a meta-analysis of randomized controlled trials. JAMA 292(23): 2874-2879. DOI: 10.1001/jama.292.23.2874

Dorian, P., Cass, D., Schwartz, B., Cooper, R., Gelaznikas, R., and Barr, A. 2002. Amiodarone as compared with lidocaine for shock-resistant ventricular fibrillation. N. Engl. J. Med. 346(12): 884-890. DOI: 10.1056/NEJMoa013029

Ellenbogen, K. A., Levine, J. H., Berger, R. D., Daubert, J. P., Winters, S. L., Greenstein, E., Shalaby, A., Schaechter, A., Subacius, H., and Kadish, A.; Defibrillators in NonIschemic Cardiomyopathy Treatment Evaluation (DEFINITE) Investigators. 2006. Are implantable cardioverter defibrillator shocks a surrogate for sudden cardiac death in patients with nonischemic cardiomyopathy? Circulation, 113(6): 776-782. DOI: 10.1161/CIRCULATIONAHA.105.561571

Eranti, A., Aro, A. L., Kerola, T., Tikkanen, J. T., Rissanen, H. A., Anttonen, O., Junttila, M. J., Knekt, P., and Huikuri, H. V. 2015. Body Mass Index as a Predictor of Sudden Cardiac Death and Usefulness of the Electrocardiogram for Risk Stratification. Am. J. Cardiol. 117(3):388-93. doi: 10.1016/j.amjcard.2015.10.057 
Every, N. R., Parsons, L., Hlatky, M. A., McDonald, K. M., Thom, D., Hallstrom, A. P., Martin, J. S., and Weaver, W. D. 1997. Use and accuracy of state death certificates for classification of sudden cardiac deaths in high-risk populations. Am. Heart J. 134(6): 1129-1132. PMID: 9424075

Falk, E. 2006. Pathogenesis of atherosclerosis. J. Am. Coll. Cardiol. 47(8s1): C7-C12. doi:10.1016/j.jacc.2005.09.068

Farioli, A., Christophi, C. A., Quarta, C. C., and Kales, S. N. 2015. Incidence of sudden cardiac death in a young active population. J. Am. Heart Assoc. 4(6):e001818. doi: 10.1161/JAHA.115.001818.

Ficker, D. M., So, E. L., Shen, W. K., Annegers, J. F., O'Brien, P. C., Cascino, G. D., and Belau, P. G. 1998. Population-based study of the incidence of sudden unexplained death in epilepsy. Neurology, 51(5): 1270-1274. PMID: 9818844. https://www.ncbi.nlm.nih.gov/pubmed/9818844

Fishman, G. I., Chugh, S. S., Dimarco, J. P., Albert, C. M., Anderson, M. E., and Bonow, R. O. 2010. Sudden cardiac death prediction and prevention: report from a National Heart, Lung, and Blood Institute and Heart Rhythm Society Workshop. Circulation, 122(22):2335-48. doi: 10.1161/CIRCULATIONAHA.110.976092.

Gehi, A. K., Stein, R. H., Metz, L. D., and Gomes, J. A. 2005. Microvolt T-wave alternans for the risk stratification of ventricular tachyarrhythmic eventsa meta-analysis. J. Am. Coll. Cardiol. 46(1): 75-82. DOI: 10.1016/j.jacc.2005.03.059

Ghanbari, H., Dalloul, G., Hasan, R., Daccarett, M., Saba, S., David, S., and Machado, C. 2009. Effectiveness of implantable cardioverter-defibrillators for the primary prevention of sudden cardiac death in women with advanced heart failure: a metaanalysis of randomized controlled trials. Arch. Intern. Med. 169(16): 1500-1506. doi: 10.1001/archinternmed.2009.255. 
Goldenberg, I., Gillespie, J., Moss, A. J., Hall, W. J., Klein, H., McNitt, S., Brown, M. W., Cygankiewicz, I., and Zareba, W.; Executive Committee of the Multicenter Automatic Defibrillator Implantation Trial II. 2010. Long-Term Benefit of Primary Prevention With an Implantable Cardioverter-Defibrillator An Extended 8-Year Follow-Up Study of the Multicenter Automatic Defibrillator Implantation Trial II. Circulation, 122(13): 1265-1271. doi: 10.1161/CIRCULATIONAHA.110.940148.

Goldenberg, I., Moss, A. J., and Zareba, W. 2006. QT interval: how to measure it and what is" normal". J. Cardiovasc. Electrophysiol. 17(3): 333-336. DOI: 10.1111/j.15408167.2006.00408.x

Goldman, A. M., Glasscock, E., Yoo, J., Chen, T. T., Klassen, T. L., and Noebels, J. L. 2009. Arrhythmia in heart and brain: KCNQ1 mutations link epilepsy and sudden unexplained death. Sci. Transl. Med. 1(2): 2ra6-2ra6. doi:

10.1126/scitranslmed.3000289

Graham, D. J., Campen, D., Hui, R., Spence, M., Cheetham, C., Levy, G., Shoor, S., and Ray, W. A. 2005. Risk of acute myocardial infarction and sudden cardiac death in patients treated with cyclo-oxygenase 2 selective and non-selective non-steroidal antiinflammatory drugs: nested case-control study. Lancet, 365(9458): 475-481. DOI: $10.1016 / \mathrm{S} 0140-6736(05) 17864-7$

Hajj, A., Ksouda, K., Peoc'h, K., Curis, E., Messali, A., Deveaux, L. L., Bloch, V., Prince, N., Mouly, S., Scherrmann, J. M., Lépine, J. P., Laplanche, J. L., Drici, M. D., and Vorspan, F. 2014. KCNH2 polymorphism and methadone dosage interact to enhance QT duration. Drug Alcohol Depend. 141: 34-38. doi:

10.1016/j.drugalcdep.2014.04.027. 
Hanna, J., Lyon, A., Hawes, A., Owens, C., and Batra, R. 2015. An Unusual Case of Syncope in a Young Female with Incidental Long QTc Interval. Heart Lung Circ. 24(2):e23-5 doi: 10.1016/j.hlc.2014.09.006

Haskell, W. L., Lee, I. M., Pate, R. R., Powell, K. E., Blair, S. N., Franklin, B. A., Macera, C. A., Heath, G. W., Thompson, P. D., and Bauman, A. 2007. Physical activity and public health: updated recommendation for adults from the American College of Sports Medicine and the American Heart Association. Circulation, 116(9): 1081. DOI: 10.1161/CIRCULATIONAHA.107.185649

Harmon, K. G., Asif, I. M., Maleszewski, J. J., Owens, D. S., Prutkin, J. M., and Salerno, J. C. 2015. Incidence, Cause, and Comparative Frequency of Sudden Cardiac Death in National Collegiate Athletic Association Athletes: A Decade in Review. Circulation, 132(1):10-9. doi: 10.1161/CIRCULATIONAHA.115.015431

Hertz, C. L., Christiansen, S. L., Ferrero-Miliani, L., Fordyce, S. L., Dahl, M., Holst, A. G., Ottesen, G. L., Frank-Hansen, R., Bundgaard, H., and Morling, N. 2015. Nextgeneration sequencing of 34 genes in sudden unexplained death victims in forensics and in patients with channelopathic cardiac diseases. Int. J. Legal Med. 129(4):793800. doi: 10.1007/s00414-014-1105-y

Hermans, J. F., Christiaans, I., van Tintelen, J. P., Wilde, A. A., and Pinto, Y. M. 2006. GENCOR: a national registry for patients and families suffering from a familial heart disease in the Netherlands. Neth. Heart J. 14(7-8):272-276. PMID: 25696657

Ho, C. Y., Lakdawala, N. K., Cirino, A. L., Lipshultz, S. E., Sparks, E., Abbasi, S. A., Kwong, R. Y., Antman, E. M., Semsarian, C., González, A., López, B., Diez, J., Orav, E. J., Colan, S. D., and Seidman, C. E. 2015. Diltiazem Treatment for Pre-Clinical Hypertrophic Cardiomyopathy Sarcomere Mutation Carriers. JACC Heart Fail. 3(2):180-8. doi: 10.1016/j.jchf.2014.08.003. 
Hohnloser, S. H., Ikeda, T., and Cohen, R. J. 2009. Evidence regarding clinical use of microvolt T-wave alternans. Heart Rhythm, 6(3): S36-S44. doi: 10.1016/j.hrthm.2008.10.011.

Hohnloser, S. H., Kuck, K. H., Dorian, P., Roberts, R. S., Hampton, J. R., Hatala, R., Fain, E., Gent, M., and Connolly, S. J.; DINAMIT Investigators. 2004. Prophylactic use of an implantable cardioverter-defibrillator after acute myocardial infarction. N. Engl. J. Med. 351(24): 2481-2488. DOI: 10.1056/NEJMoa041489

Huikuri, H. V., Castellanos, A., and Myerburg, R. J. 2001. Sudden death due to cardiac arrhythmias. N. Engl. J. Med. (20): 1473-1482. DOI: 10.1056/NEJMra000650

Huikuri, H. V., Mäkikallio, T. H., Raatikainen, M. J., Perkiömäki, J., Castellanos, A., and Myerburg, R. J. 2003. Prediction of sudden cardiac death appraisal of the studies and methods assessing the risk of sudden arrhythmic death. Circulation, 108(1): 110-115. DOI: 10.1161/01.CIR.0000077519.18416.43

Huikuri, H. V., Tapanainen, J. M., Lindgren, K., Raatikainen, P., Mäkikallio, T. H., Juhani Airaksinen, K. E., and Myerburg, R. J. 2003. Prediction of sudden cardiac death after myocardial infarction in the beta-blocking era. J. Am. Coll. Cardiol. 42(4): 652-658. doi. 10.1016/S0735-1097(03)00783-6

Ikeda, T., Yoshino, H., Sugi, K., Tanno, K., Shimizu, H., Watanabe, J., Kasamaki, Y., Yoshida, A., and Kato, T. 2006. Predictive value of microvolt T-wave alternans for sudden cardiac death in patients with preserved cardiac function after acute myocardial infarction: results of a collaborative cohort study. J. Am. Coll. Cardiol. 48(11): 2268-2274. DOI: 10.1016/j.jacc.2006.06.075

Ilgenli, T. F., Tokatli, A., Akpınar, O., and Kılıçaslan, F. 2015. The Effects of Cigarette Smoking on the Tp-e Interval, Tp-e/QT Ratio and Tp-e/QTc Ratio. Adv. Clin. Exp. Med. 24(6): 973-978. doi: 10.17219/acem/28114. 
Iribarren, C., Crow, R. S., Hannan, P. J., Jacobs, D. R. Jr, and Luepker, R.V. 1998. Validation of death certificate diagnosis of out-of-hospital sudden cardiac death. Am. J. Cardiol. 82(1): 50-53. doi.10.1016/S0002-9149(98)00240-9

Jackowski, C., Schwendener, N., Grabherr, S., and Persson, A. 2013. Post-mortem cardiac 3T magnetic resonance imaging: visualization of sudden cardiac death? J. Am. Coll. Cardiol. 62(7):617-29. doi: 10.1016/j.jacc.2013.01.089.

Jia, G., Cheng, G., Gangahar, D. M., and Agrawal, D.K. 2006. Insulin-like growth factor-1 and TNF-alpha regulate autophagy through c-jun N-terminal kinase and Akt pathways in human atherosclerotic vascular smooth cells. Immunol. Cell Biol. 84(5): 448-454. DOI: $10.1111 / \mathrm{j} .1440-1711.2006 .01454 . \mathrm{x}$

Joshi, R. K., Jyoti, A., Aggarwal, N., Aggarwal, M., and Joshi, R. 2015. Contained rupture of mycotic aneurysm of the left circumflex coronary artery in a child. World J. Pediatr. Congenit. Heart Surg. 6(1): 111-114. doi: 10.1177/2150135114551994.

Kamei, S., Sato, N., Harayama, Y., Nunotani, M., Takatsu, K., Shiozaki, T., Hayashi, T., and Asamura, H. 2014. Molecular analysis of potassium ion channel genes in sudden death cases among patients administered psychotropic drug therapy: are polymorphisms in LQT genes a potential risk factor? J. Hum. Genet. 59(2): 95-99. doi: 10.1038/jhg.2013.125

Kannel, W. B., Cupples, L. A., and D'Agostino, R. B. 1987. Sudden death risk in overt coronary heart disease: the Framingham Study. Am. Heart J. 113(3): 799-804. PMID: 3825868

Kannel, W. B., Wilson, P. W., D'Agostino, R.B., and Cobb, J. 1998. Sudden coronary death in women. Am. Heart J. 136(2): 205-212. DOI: 10.1053/hj.1998.v136.90226 
Kasama, S., Toyama, T., and Kurabayashi, M. 2015. Serial ${ }^{123}$ I-metaiodobenzylguanidine imaging predicts the risk of sudden cardiac death in patients with chronic heart failure. Int. J. Cardiol. 179: 82-83. doi: 10.1016/j.ijcard.2014.10.047

Kauferstein, S., Kiehne, N., Peigneur, S., Tytgat, J., and Bratzke, H. 2013. Cardiac channelopathy causing sudden death as revealed by molecular autopsy. Int. J. Legal Med. 127(1): 145-151. doi: 10.1007/s00414-012-0679-5.

Keating, M. T., and Sanguinetti, M. C. 2001. Molecular and cellular mechanisms of cardiac arrhythmias. Cell, 104(4): 569-580. doi.10.1016/S0092-8674(01)00243-4

Kenny, D., and Martin, R. 2011. Drowning and sudden cardiac death. Arch. Dis. Childhood, 96(1): 5-8. doi: 10.1136/adc.2010.185215.

Korte, A. K., Derde, L., van Wijk, J., and Tjan, D. H. 2015. Sudden cardiac arrest as a presentation of Brugada syndrome unmasked by thyroid storm. BMJ Case Rep. 2015. pii: bcr2015212351. doi: 10.1136/bcr-2015-212351.

Kostera-Pruszczyk, A., Potulska-Chromik, A., Pruszczyk, P., Bieganowska, K., MiszczakKnecht, M., Bienias, P., Szczałuba, K., Lee, H. Y., Quinn, E., Ploski, R., Kaminska, A., and Ptáček, L. J. 2015. Andersen-Tawil syndrome: Report of 3 novel mutations and high risk of symptomatic cardiac involvement. Muscle Nerve, 51(2):192-6. doi: 10.1002/mus.24293.

Krisciukaitis, A., Šimoliūnienė, R., Macas, A., Petrolis, R., Drègūnas, K., Bakšytė, G., Pieteris, L., Bertašienè, Z., and Žaliūnas, R. 2014. Detection and evaluation of ventricular repolarization alternans: An approach to combined ECG, thoracic impedance, and beat-to-beat heart rate variability analysis. Medicina, 50(6):345-52. doi: 10.1016/j.medici.2014.11.004 
Kurl, S., Jae, S. Y., Kauhanen, J., Ronkainen, K., Rauramaa, R., and Laukkanen, J. A. 2015. Exercise cardiac power and the risk of sudden cardiac death in a long-term prospective study. Int. J. Cardiol. 181: 155-159. doi: 10.1016/j.ijcard.2014.12.023.

Kwon, H. W., Lee, S. Y., Kwon, B. S., Kim, G. B., Bae, E. J., Kim, W. H., Noh, C. I., Cho, S. I., and Park, S. S. 2012. Long QT Syndrome and Dilated Cardiomyopathy with SCN5A p. R1193Q Polymorphism: Cardioverter-Defibrillator Implantation at 27 Months. Pacing Clin. Electrophysio.1 35(8): e243-e246. doi: 10.1111/j.15408159.2012.03409.x.

Lubkemeier, I., Bosen, F., Kim, J. S., Sasse, P., Malan, D., Fleischmann, B. K., and Willecke, K. 2015. The Human Connexin43E42K Mutation from a Sudden Infant Death Victim Leads to Impaired Ventricular Activation and Neonatal Death in Mice. Circ. Cardiovasc. Genet. 8(1):21-9. doi: 10.1161/CIRCGENETICS.114.000793.

Lanfear, D. E., Jones, P. G., Marsh, S., Cresci, S., McLeod, H. L., and Spertus, J. A. 2005. $\beta 2$-adrenergic receptor genotype and survival among patients receiving $\beta$-blocker therapy after an acute coronary syndrome. JAMA 294(12): 1526-1533. DOI: 10.1001/jama.294.12.1526

Laposata, E. A., Hale, P. Jr, and Poklis, A. 1988. Evaluation of sudden death in psychiatric patients with special reference to phenothiazine therapy: forensic pathology. J. Forensic Sci. 33(2): 432-440. PMID: 2897420

Lariccia, V., Nasti, A. A., Alessandrini, F., Pesaresi, M., Gratteri, S., Tagliabracci, A., and Amoroso, S. 2014. Identification and functional analysis of a new putative caveolin-3 variant found in a patient with sudden unexplained death. J. Biomed. Sci. 21: 58. doi: 10.1186/1423-0127-21-58.

Leaf, A., Albert, C. M., Josephson, M., Steinhaus, D., Kluger, J., Kang, J. X., Cox, B., Zhang, H., and Schoenfeld, D.; Fatty Acid Antiarrhythmia Trial Investigators. 2005. 
Prevention of fatal arrhythmias in high-risk subjects by fish oil n-3 fatty acid intake. Circulation, 112(18): 2762-2768. DOI: 10.1161/CIRCULATIONAHA.105.549527

Leong, I. U., Stuckey, A., Lai, D., Skinner, J. R., and Love, D. R. 2015. Assessment of the predictive accuracy of five in silico prediction tools, alone or in combination, and two metaservers to classify long QT syndrome gene mutations. BMC Med. Genet. 16: 34. doi: 10.1186/s12881-015-0176-z.

Liao, P., and Soong, T. W. 2009. CaV1. 2 channelopathies: from arrhythmias to autism, bipolar disorder, and immunodeficiency. Pflugers Arch. -Eur. J. Physiol. 460(2): 353359. doi: 10.1007/s00424-009-0753-0.

Liberthson, R. R. 1996. Sudden death from cardiac causes in children and young adults. N. Engl. J. Med. 334(16): 1039-1044. DOI: 10.1056/NEJM199604183341607

Link, M. S., and Estes, 3rd N. A. 2007. Mechanically induced ventricular fibrillation (commotio cordis). Heart Rhythm, 4(4): 529-532. DOI: 10.1016/j.hrthm.2006.12.020

Luu, M., Stevenson, W. G., Stevenson, L. W., Baron, K., and Walden, J. 1989. Diverse mechanisms of unexpected cardiac arrest in advanced heart failure. Circulation, 80(6): 1675-1680. doi.10.1161/01.CIR.80.6.1675

Marquez, M. F., Totomoch-Serra, A., Burgoa, J. A., Méndez, A., Gómez-Flores, J. R., Nava, S., and Cardenas, M. 2015. Abnormal electroencephalogram, epileptic seizures, structural congenital heart disease and aborted sudden cardiac death in AndersenTawil syndrome. Int. J. Cardiol. 180:206-9. DOI: 10.1016/j.ijcard.2014.11.157

Makikallio, T. H., Barthel, P., Schneider, R., Bauer, A., Tapanainen, J. M., Tulppo, M. P., Schmidt, G., and Huikuri, H. V. 2005. Prediction of sudden cardiac death after acute myocardial infarction: role of Holter monitoring in the modern treatment era. Eur. Heart J. 26(8): 762-769. DOI: 10.1093/eurheartj/ehi188 
Manson, J. E., Hu, F. B., Rich-Edwards, J. W., Colditz, G. A., Stampfer, M. J., Willett, W. C., Speizer, F. E., and Hennekens, C.H. 1999. A prospective study of walking as compared with vigorous exercise in the prevention of coronary heart disease in women. N. Engl. J. Med. 341(9): 650-658. DOI: 10.1056/NEJM199908263410904

Maron, B. J., Shirani, J., Poliac, L. C., Mathenge, R., Roberts, W. C., and Mueller, F. O. 1996. Sudden death in young competitive athletes: clinical, demographic, and pathological profiles. JAMA 276(3): 199-204. doi:10.1001/jama.1996.03540030033028

McNamara, D. M., MacGowan, G. A., and London, B. 2002. Clinical importance of $\beta$ adrenoceptor polymorphisms in cardiovascular disease. Am. J. Pharmacogenomics, 2(2): 73-78. DOI: 10.2165/00129785-200202020-00001

Mechakra, A., Vincent, Y., Chevalier, P., Millat, G., Ficker, E., Jastrzebski, M., Poulin, H., Pouliot, V., Chahine, M., and Christé, G. 2014. The variant hERG/R148W associated with LQTS is a mutation that reduces current density on co-expression with the WT. Gene, 536(2): 348-356. doi: 10.1016/j.gene.2013.11.072.

Mensah, G. A., Mokdad, A. H., Ford, E. S., Greenlund, K. J., and Croft, J. B. 2005. State of disparities in cardiovascular health in the United States. Circulation, 111(10): 12331241. DOI: 10.1161/01.CIR.0000158136.76824.04

Meregalli, P. G., Tan, H. L., Probst, V., Koopmann, T. T., Tanck, M. W., Bhuiyan, Z. A., Sacher, F., Kyndt, F., Schott, J. J., Albuisson, J., Mabo, P., Bezzina, C. R., Le Marec, H., and Wilde, A. A. 2009. Type of SCN5A-mutation determines clinical severity and degree of conduction slowing in loss-of-function sodium channelopathies. Heart Rhythm, 6(3): 341-348. doi: 10.1016/j.hrthm.2008.11.009. 
Michaud, K., Grabherr, S., Jackowski, C., Bollmann, M. D., Doenz, F., and Mangin, P. 2014. Postmortem imaging of sudden cardiac death. Int. J. Legal Med.128(1):127-37. doi: 10.1007/s00414-013-0819-6.

Millat, G., Chanavat, V., and Rousson, R. 2014. Evaluation of a New High-Throughput NextGeneration Sequencing Method Based on a Custom AmpliSeq ${ }^{\mathrm{TM}}$ Library and Ion Torrent $\mathrm{PGM}^{\mathrm{TM}}$ Sequencing for the Rapid Detection of Genetic Variations in Long QT Syndrome. Mol. Diagn. Ther.18(5):533-9. doi: 10.1007/s40291-014-0099-y.

Mitchell, L. B., Pineda, E. A., Titus, J. L., Bartosch, P. M., and Benditt, D. G. 2002. Sudden death in patients with implantable cardioverter defibrillators The importance of postshock electromechanical dissociation. J. Am. Coll. Cardiol. 39(8): 1323-1328. doi.10.1016/S0735-1097(02)01784-9

Mitchell, L. B., Powell, J. L., Gillis, A. M., Kehl, V., and Hallstrom, A. P. AVID Investigators. 2003. Are lipid-lowering drugs also antiarrhythmic drugs? An analysis of the Antiarrhythmics versus Implantable Defibrillators (AVID) trial. J. Am. Coll. Cardiol. 42(1): 81-87. doi.10.1016/S0735-1097(03)00498-4

Morrison, L. J., Dorian, P., Long, J., Vermeulen, M., Schwartz, B., Sawadsky, B., Frank. J., Cameron, B., Burgess, R., Shield, J., Bagley, P., Mausz, V., Brewer, J. E., and Lerman, B. B. Steering Committee, Central Validation Committee, Safety and Efficacy Committee. 2005. Out-of-hospital cardiac arrest rectilinear biphasic to monophasic damped sine defibrillation waveforms with advanced life support intervention trial (ORBIT). Resuscitation, 66(2): 149-157. DOI: 10.1016/j.resuscitation.2004.11.031

Moss, A. J., Zareba, W., Hall, W. J., Klein, H., Wilber, D. J., Cannom, D. S., Daubert, J. P., Higgins, S. L., Brown, M. W., and Andrews, M. L. Multicenter Automatic Defibrillator Implantation Trial II Investigators. 2002. Prophylactic implantation of a 
defibrillator in patients with myocardial infarction and reduced ejection fraction. N. Engl. J. Med. 346(12): 877-883. DOI: 10.1056/NEJMoa013474

Mozaffarian, D., Benjamin, E. J., Go, A. S., Arnett, D. K., Blaha, M. J., and Cushman, M. 2015. Executive Summary: Heart Disease and Stroke Statistics—2015: Update A Report From the American Heart Association. Circulation, 131(4):e29-e322. doi: 10.1161/CIR.0000000000000219.

Mukherjee, D., Nissen, S. E., and Topol, E. J. 2001. Risk of cardiovascular events associated with selective COX-2 inhibitors. JAMA 286(8): 954-959. DOI: 10.1001/jama.286.8.954

Murray, C. J. L., and Lopez, A. D. 1997. Alternative projections of mortality and disability by cause 1990-2020: Global Burden of Disease Study. Lancet, 349(9064): 14981504. DOI: $10.1016 / \mathrm{S} 0140-6736(96) 07492-2$

Myerburg, R. J., Interian, A. Jr., Mitrani, R. M., Kessler, K. M., and Castellanos, A. 1997. Frequency of sudden cardiac death and profiles of risk. Am. J. Cardiol. 80(5B):10F19F. doi. 10.1016/S0002-9149(97)00477-3

Myerburg, R. J. 2002. Scientific gaps in the prediction and prevention of sudden cardiac death. J. Cardiovasc. Electrophysiol. 13(7): 709-723. doi/10.1046/j.15408167.2002.00709.x

Myerburg, R.J., and Junttila, M. J. 2012. Sudden cardiac death caused by coronary heart disease. Circulation, 125(8):1043-52. doi:10.1161/CIRCULATIONAHA.111.023846.

Nakata, T., Hashimoto, A., Moroi, M., Tamaki, N., Nishimura, T., Hasebe, N., Kikuchi, K., and Nakatani, E. 2015. Sudden death prediction by C-reactive protein, electrocardiographic findings, and myocardial fatty acid uptake in haemodialysis patients: analysis of a multicentre prospective cohort sub-study. Eur. Heart J.

Cardiovasc. Imaging, pii: jev294. DOI: 10.1093/ehjci/jev294 
Narula, N., Tester, D. J., Paulmichl, A., Maleszewski, J. J., and Ackerman, M. J. 2015. Postmortem Whole Exome Sequencing with Gene-Specific Analysis for AutopsyNegative Sudden Unexplained Death in the Young: A Case Series. Pediatr. Cardiol: 36(4):768-78. doi: 10.1007/s00246-014-1082-4

Okrainec, K., Banerjee, D. K., and Eisenberg, M. J. 2004. Coronary artery disease in the developing world. Am. Heart J. 148(1): 7-15. DOI: 10.1016/j.ahj.2003.11.027

Ota, K., and Bratincsak, A. 2014. Atrial Fibrillation Induced by Commotio Cordis Secondary to a Blunt Chest Trauma in a Teenage Boy. Pediatrics, 135(1):e199-201. doi: 10.1542/peds.2014-1972.

Pachon, R., Bravo, C., and Niemiera, M. 2015. Sudden cardiac death as a presentation of anomalous origin of the left coronary artery from pulmonary artery in a young adult. Eur. Heart J. Acute Cardiovasc. Care, 4(6):589-90. doi: 10.1177/2048872614562969.

Papadakis, M., Sharma, S., Cox, S., Sheppard, M. N., Panoulas, V. F., and Behr, E. R. 2009. The magnitude of sudden cardiac death in the young: a death certificate-based review in England and Wales. Europace, 11(10):1353-8. doi: 10.1093/europace/eup229

Parish, D. C., Dinesh Chandra, K. M., and Dane, F. C. 2003. Success changes the problem: why ventricular fibrillation is declining, why pulseless electrical activity is emerging, and what to do about it. Resuscitation, 58(1): 31-35. doi.10.1016/S03009572(03)00104-7.

Park, D. S., Cerrone, M., Morley, G., Vasquez, C., Fowler, S., Liu, N., Bernstein, S. A, Liu, F.Y., Zhang, J., Rogers, C. S., Priori, S. G., Chinitz, L. A., and Fishman, G. I. 2015. Genetically engineered SCN5A mutant pig hearts exhibit conduction defects and arrhythmias. J. Clin. Invest. 125(1):403-12. doi: 10.1172/JCI76919.

Partemi, S., Cestèle, S., Pezzella, M., Campuzano, O., Paravidino, R., Pascali, V. L., Zara, F., Tassinari, C. A., Striano, S., Oliva, A., Brugada, R., Mantegazza, M., and Striano, P. 
2013. Loss-of-function KCNH2 mutation in a family with long QT syndrome, epilepsy, and sudden death. Epilepsia, 54(8): e112-e116. doi: 10.1111/epi.12259.

Pérez-Serra, A., Toro, R., Campuzano, O., Sarquella-Brugada, G., Berne, P., Iglesias, A., Mangas, A., Brugada, J., and Brugada, R. 2015. A Novel Mutation in Lamin A/C Causing Familial Dilated Cardiomyopathy Associated with Sudden Cardiac Death. J. Card. Fail. 21(3):217-25. doi: 10.1016/j.cardfail.2014.12.003.

Phillips, S. B., Batlivala, S., and Knudson, J. D. 2015. Unusual cause of aborted sudden cardiac death in a teen athlete: homozygosity for the $4 \mathrm{G}$ allele of the plasminogen activase inhibitor type 1 gene. Cardiol.Young, 25(7):1428-30. doi: 10.1017/S104795111400242X.

Podrid, P. J., and Myerburg, R. J. 2005. Epidemiology and stratification of risk for sudden cardiac death. Clin. Cardiol. 28(Suppl 1): 3-11. PMID: 16450807.

Postema, P. G. and Wilde, A. A. 2008. Do patients with long QT syndrome remain at risk for sudden cardiac death after 40 years of age? Nat. Clin. Pract. Cardiovasc. Med. 5(10):602-3. doi: 10.1038/ncpcardio1305.

Rahimi, K., Majoni, W., Merhi, A., and Emberson, J. 2012. Effect of statins on ventricular tachyarrhythmia, cardiac arrest, and sudden cardiac death: a meta-analysis of published and unpublished evidence from randomized trials. Eur. Heart J. 33(13): 1571-1581. doi: 10.1093/eurheartj/ehs005.

Rai, V., Rao, V. H., Shao, Z., and Agrawal, D. K. 2016. Dendritic Cells Expressing Triggering Receptor Expressed on Myeloid Cells-1 Correlate with Plaque Stability in Symptomatic and Asymptomatic Patients with Carotid Stenosis. PloS One, 11(5), e0154802. doi: 10.1371/journal.pone.0154802.

Raitt, M. H., Connor, W. E., Morris, C., Kron, J., Halperin, B., Chugh, S. S., McClelland, J., Cook, J., MacMurdy, K., Swenson, R., Connor, S.L., et al. 2005. Fish oil 
supplementation and risk of ventricular tachycardia and ventricular fibrillation in patients with implantable defibrillators: a randomized controlled trial. JAMA 293(23): 2884-2891. DOI: 10.1001/jama.293.23.2884

Rana, B. S., Lim, P. O., Naas, A. A., Ogston, S. A., Newton, R. W., Jung, R. T., Morris, A. D., and Struthers, A. D. 2005. QT interval abnormalities are often present at diagnosis in diabetes and are better predictors of cardiac death than ankle brachial pressure index and autonomic function tests. Heart, 91(1): 44-50. DOI:

10.1136/hrt.2003.017632

Rao, B. H. 2014. Global burden of Sudden Cardiac Death and insights from India. Indian Heart J. 66 Suppl1:S18-23. doi: 10.1016/j.ihj.2013.11.009.

Rao, V. H., Kansal, V., Stoupa, S., and Agrawal, D. K. 2014. MMP-1 and MMP-9 regulate epidermal growth factor-dependent collagen loss in human carotid plaque smooth muscle cells. Physiol. Rep. 2(2):e00224. doi: 10.1002/phy2.224.

Rao, V. H., Rai, V., Stoupa, S., and Agrawal, D. K 2015. Blockade of Ets-1 attenuates epidermal growth factor-dependent collagen loss in human carotid plaque smooth muscle cells. Am. J. Physiol. 309(6): H1075-1086. doi: 10.1152/ajpheart.00378.2015.

Rao, V. H., Rai, V., Stoupa, S., Subramanian, S., and Agrawal, D. K. 2016. Tumor necrosis factor-alpha regulates triggering receptor expressed on myeloid cells-1-dependent matrix metalloproteinases in the carotid plaques of symptomatic patients with carotid stenosis. Atherosclerosis, 248: 160-169. doi: 10.1016/j.atherosclerosis.2016.03.021.

Rautaharju, P. M., Zhang, Z. M., Haisty, W.K. Jr, Kucharska-Newton, A. M., Rosamond, W. D., and Soliman, E. Z. 2015. Electrocardiographic repolarization-related predictors of coronary heart disease and sudden cardiac deaths in men and women with cardiovascular disease in the Atherosclerosis Risk in Communities (ARIC) study. J. Electrocardiol. 48(1):101-11. doi: 10.1016/j.jelectrocard.2014.10.004 
Ray, W. A., Chung, C. P., Murray, K. T., Hall, K., and Stein, C. M. 2009. Atypical antipsychotic drugs and the risk of sudden cardiac death. N. Engl. J. Med. 360(3): 225-235. doi: 10.1056/NEJMoa0806994.

Ray, W. A., Meredith, S., Thapa, P. B., Hall, K., and Murray, K. T. 2004. Cyclic antidepressants and the risk of sudden cardiac death. Clin. Pharmacol. Ther. 75(3): 234-241. DOI: 10.1016/j.clpt.2003.09.019

Reddy, P. R., Reinier, K., Singh, T., Mariani, R., Gunson, K., Jui, J., and Chugh, S. S. 2009. Physical activity as a trigger of sudden cardiac arrest: The Oregon Sudden Unexpected Death Study. Int. J. Cardiol. 131(3): 345-349. doi: 10.1016/j.ijcard.2007.10.024.

Robaei, D., Ford, T., and Ooi, S. Y. 2015. Ankyrin-B Syndrome: A Case of Sinus Node Dysfunction, Atrial Fibrillation and Prolonged QT in a Young Adult. Heart Lung Circ. 24(2):e31-4. doi: 10.1016/j.hlc.2014.09.013.

Roberts, W. C. 1990. Sudden cardiac death: a diversity of causes with focus on atherosclerotic coronary artery disease. Am. J. Cardiol. 65(4): 13B-19B. PMID: 2404394.

Roger, V. L., Farkouh, M. E., Weston, S. A., Reeder, G. S., Jacobsen, S. J., Zinsmeister, A. R., Yawn, B. P., Kopecky, S. L., and Gabriel, S. E. 2000. Sex differences in evaluation and outcome of unstable angina. JAMA 283(5): 646-652. doi:10.1001/jama.283.5.646

Rozanski, A., Blumenthal, J. A., Davidson, K. W., Saab, P. G., and Kubzansky, L. 2005. The epidemiology, pathophysiology, and management of psychosocial risk factors in cardiac practiceThe emerging field of behavioral cardiology. J. Am. Coll. Cardiol. 45(5): 637-651. DOI: 10.1016/j.jacc.2004.12.005 
Sanguinetti, M. C. 2010. HERG1 channelopathies. Pflugers Arch. -Eur. J. Physiol. 460(2): 265-276. doi: 10.1007/s00424-009-0758-8.

Schmidt. A. 2013. Crime scene investigation approach to sudden cardiac death. J. Am. Coll. Cardiol. 62(7):630-1. doi: 10.1016/j.jacc.2013.04.055

Skinner, J. R., Marquis-Nicholson, R., Luangpraseuth, A., Cutfield, R., Crawford, J., and Love, D. R. 2014. Diabetic Dead-in-Bed Syndrome: A Possible Link to a Cardiac Ion Channelopathy. Case Rep. Med. 2014:647252. doi: 10.1155/2014/647252.

Soo, L., Huff, N., Gray, D., and Hampton, J. R. 2001. Geographical distribution of cardiac arrest in Nottinghamshire. Resuscitation, 48(2): 137-147. doi.10.1016/S03009572(00)00248-3

Sotoodehnia, N., Siscovick, D. S., Vatta, M., Psaty, B. M., Tracy, R. P., Towbin, J. A., Lemaitre, R. N., Rea, T. D., Durda, J. P., Chang, J. M., Lumley, T. S., Kuller, L. H., Burke, G. L., and Heckbert, S. R. 2006. $\beta 2$-Adrenergic receptor genetic variants and risk of sudden cardiac death. Circulation, 113(15): 1842-1848. DOI:

10.1161/CIRCULATIONAHA.105.582833

Sottas, V., Rougier, J. S., Jousset, F., Kucera, J. P., Shestak, A., Makarov, L.M., Zaklyazminskaya, E. V., and Abriel, H. 2013. Characterization of 2 Genetic Variants of Nav1. 5-Arginine 689 Found in Patients with Cardiac Arrhythmias. J. Cardiovasc. Electrophysiol. 24(9): 1037-1046. doi: 10.1111/jce.12173.

Splawski, I., Tristani-Firouzi, M., Lehmann, M. H., Sanguinetti, M. C., and Keating, M. T. 1997. Mutations in the hminK gene cause long QT syndrome and suppress $1 \mathrm{Ks}$ function. Nat. Genet. 17(3): 338-340. DOI: 10.1038/ng1197-338

Stecker, E. C., Vickers, C., Waltz, J., Socoteanu, C., John, B. T., Mariani, R., McAnulty, J. H., Gunson, K., Jui, J., and Chugh, S. S. 2006. Population-based analysis of sudden cardiac death with and without left ventricular systolic dysfunctionTwo-year findings 
from the Oregon Sudden Unexpected Death Study. J. Am. Coll. Cardiol. 47(6): 11611166. DOI: 10.1016/j.jacc.2005.11.045.

Steptoe, A., and Kivimaki, M. 2013. Stress and cardiovascular disease: an update on current knowledge. Annu. Rev. Public Health 34: 337-354. doi: 10.1146/annurev-publhealth$031912-114452$.

Straus, S., Bleumink, G. S., Dieleman, J. P., van der Lei, J., Stricker, B. H., and Sturkenboom, M. C. 2004. The incidence of sudden cardiac death in the general population. J. Clin. Epidemiol. 57(1): 98-102. DOI: 10.1016/S0895-4356(03)00210-5

Straus, S. M., Bleumink, G. S., Dieleman, J. P., van der Lei, J., 't Jong G. W., Kingma, J. H., Sturkenboom, M. C., and Stricker, B. H. 2004. Antipsychotics and the risk of sudden cardiac death. Arch. Intern. Med. 164(12): 1293-1297. DOI: 10.1001/archinte.164.12.1293.

Straus, S. M., Kors, J. A., De Bruin, M. L., van der Hooft, C. S., Hofman, A., Heeringa, J., Deckers, J. W., Kingma, J. H., Sturkenboom, M. C., Stricker, B. H., and Witteman, J. C. 2006. Prolonged QTc interval and risk of sudden cardiac death in a population of older adults. J. Am. Coll. Cardiol. 47(2): 362-367. DOI: 10.1016/j.jacc.2005.08.067

Straus, S. M., Sturkenboom, M. C., Bleumink, G. S., Dieleman, J. P., van der Lei, J., de Graeff, P. A., Kingma, J. H., and Stricker, B. H. 2005. Non-cardiac QTc-prolonging drugs and the risk of sudden cardiac death. Eur. Heart J. 26(19): 2007-2012. DOI: 10.1093/eurheartj/ehi312

Suessbrich, H., Schönherr, R., Heinemann, S. H., Attali, B., Lang, F., and Busch, A. E. 1997. The inhibitory effect of the antipsychotic drug haloperidol on HERG potassium channels expressed in Xenopus oocytes. Br. J. Pharmacol. 120(5): 968-974. DOI: 10.1038/sj.bjp.0700989 
Surber, R., Hensellek, S., Prochnau, D., Werner, G. S., Benndorf, K., Figulla, H. R., and Zimmer, T. 2008. Combination of cardiac conduction disease and long QT syndrome caused by mutation T1620K in the cardiac sodium channel. Cardiovasc. Res. 77(4): 740-748. DOI: $10.1093 / \mathrm{cvr} / \mathrm{cvm} 096$

Tan, B. H., Pundi, K. N., Van Norstrand, D. W., Valdivia, C. R., Tester, D. J., MedeirosDomingo, A., Makielski, J. C., and Ackerman, M. J. 2010. Sudden infant death syndrome-associated mutations in the sodium channel beta subunits. Heart Rhythm, 7(6): 771-778. doi: 10.1016/j.hrthm.2010.01.032.

Thorgeirsson, G., Thorgeirsson, G., Sigvaldason, H., and Witteman, J. 2005. Risk factors for out-of-hospital cardiac arrest: the Reykjavik Study. Eur. Heart J. 26(15): 1499-1505. DOI: $10.1093 /$ eurheartj/ehi 179

Turakhia, M., and Tseng, Z. H. 2007. Sudden cardiac death: epidemiology, mechanisms, and therapy. Curr. Probl. Cardiol. 32(9): 501-546. DOI: 10.1016/j.cpcardiol.2007.05.002

Uehara, M., Funabashi, N., Takaoka, H., Ozawa, K., and Kobayashi, Y. 2015. The CHADS2 Score is a Useful Predictor of Coronary Arteriosclerosis on 320 Slice CT and May Correlate with Prognosis in Subjects with Atrial Fibrillation. Int. J. Cardiol. 179:84-9. doi: 10.1016/j.ijcard.2014.10.151.

Uzieblo-Zyczkowska, B., Gielerak, G., Siedlecki, P., and Pająk, B. 2014. Genetic Diversity of SCN5A Gene and Its Possible Association with the Concealed Form of Brugada Syndrome Development in Polish Group of Patients. Biomed. Res .Int. 2014:462609. doi: $10.1155 / 2014 / 462609$.

Vaduganathan, M., Patel, R. B., Shah, S. J., and Butler, J. 2016. Sudden cardiac death in heart failure with preserved ejection fraction: a target for therapy? Heart Fail. Rev. 21(4):455-62. doi: 10.1007/s10741-016-9525-z. 
van Norstrand, D. W., Asimaki, A., Rubinos, C., Dolmatova, E., Srinivas, M., Tester, D. J., Saffitz, J. E., Duffy, H. S., and Ackerman, M. J. 2012. Connexin43 mutation causes heterogeneous gap junction loss and sudden infant death. Circulation, 125(3): 474481. doi: 10.1161/CIRCULATIONAHA.111.057224.

Vatta, M., Ackerman, M. J., Ye, B., Makielski, J. C., Ughanze, E. E., Taylor, E. W., Tester, D. J., Balijepalli, R. C., Foell, J. D., Li, Z., Kamp, T. J., and Towbin, J. A. 2006. Mutant caveolin-3 induces persistent late sodium current and is associated with longQT syndrome. Circulation, 114(20): 2104-2112. DOI:

\subsection{1/CIRCULATIONAHA.106.635268}

Virk, I. S., and Ip, R. 2005. Prophylactic Use of an Implantable Cardioverter-Defibrillator After Acute Myocardial Infarction. Congestive Heart Failure, 11(3): 157-158. DOI: 10.1111/j.1527-5299.2005.04172.x

Vyas, A. K., Guo, H., Moss, A. J., Olshansky, B., McNitt, S. A., Hall, W. J., Zareba, W., Steinberg, J. S., Fischer, A., Ruskin, J., and Andrews, M. L. MADIT-II Research Group. 2006. Reduction in ventricular tachyarrhythmias with statins in the Multicenter Automatic Defibrillator Implantation Trial (MADIT)-II. J. Am. Coll. Cardiol. 47(4): 769-773. DOI: 10.1016/j.jacc.2005.09.053

Wannamethee, G., Shaper, A. G., Macfarlane, P. W., and Walker, M. 1995. Risk factors for sudden cardiac death in middle-aged British men. Circulation, 91(6): 1749-1756. doi.10.1161/01.CIR.91.6.1749.

Yagishita, D., Chui, R. W., Yamakawa, K., Rajendran, P. S., Ajijola, O. A., Nakamura, K., So, E. L., Mahajan, A., Shivkumar, K., and Vaseghi, M. 2014. Sympathetic Nerve Stimulation, Not Circulating Norepinephrine, Modulates T-Peak to T-End Interval by Increasing Global Dispersion of Repolarization. Circ. Arrhythm. Electrophysiol. 2015 Feb;8(1):174-85. doi: 10.1161/CIRCEP.114.002195. 
Yang, K. M., Lee, S. Y., Kim, Y. S., Seo, J. S., Lee, Y. S., and Seo, J. W. 2008. Guidelines for forensic assessment of natural unexpected cardiovascular death. Basic Appl. Pathol. 1(4):155-163. DOI: 10.1111/j.1755-9294.2008.00033.x.

Zeng, Z., Xie, Q., Huang, Y., Zhao, Y., Li, W., and Huang, Z. 2016. p.D1690N sodium voltage-gated channel alpha subunit 5 mutation reduced sodium current density and is associated with Brugada syndrome. Mol. Med. Rep. 13(6):5216-22. doi: 10.3892/mmr.2016.5162.

Zhao, Y., Cao, H., Song, Y., Feng, Y., Ding, X., Pang, M., Zhang, Y., Zhang, H,, Ding, J., and Xia, X. 2016. Identification of novel mutations including a double mutation in patients with inherited cardiomyopathy by a targeted sequencing approach using the Ion Torrent PGM system. Int. J. Mol. Med. 37(6):1511-20. doi: 10.3892/ijmm.2016.2565.

Zheng, Z. J., Croft, J. B., Giles, W. H., and Mensah, G. A. 2001. Sudden cardiac death in the United States, 1989 to 1998. Circulation, 104(18): 2158-2163. doi.10.1161/hc4301.098254

Zipes, D. P., and Rubart, M. 2006. Neural modulation of cardiac arrhythmias and sudden cardiac death. Heart Rhythm, 3(1):108-13. DOI: 10.1016/j.hrthm.2005.09.021

Zipes, D. P., and Wellens, H. J. J. 1998. Sudden cardiac death. Circulation, 98(21): 23342351. doi.10.1161/01.CIR.98.21.2334. 
Table 1: Cardiac diseases and arrhythmias accounting for sudden cardiac death: Ventricular fibrillation is the most common arrhythmia accounting for SCD. STEMI- ST-segment elevated myocardial infarction; NSTEMI- non-ST segment elevated MI; VT-ventricular tachycardia; VF-ventricular fibrillation; CHE-congestive heart failure (de Luna et al. 1989; Turakhia and Tseng 2007).

\begin{tabular}{|l|l|l|l|}
\hline \multicolumn{2}{|l|}{ Heart disease } & $\begin{array}{l}\text { Predominant } \\
\text { mechanism }\end{array}$ & $\begin{array}{l}\text { Accounts for } \\
\text { percent SCD }\end{array}$ \\
\hline \multirow{2}{*}{ Myocardial infarction } & STEMI & VT/VF & $10 \%$ \\
\cline { 2 - 4 } & NSTEMI & VT/VF & $2 \%$ \\
\hline \multirow{2}{*}{ Post myocardial infarction } & $\begin{array}{l}1^{\text {st }} \\
3 \text { months }\end{array}$ & VT/VF & $25 \%$ \\
\cline { 2 - 4 } & $1^{\text {st }}$ year & VT/VF & $50 \%$ \\
\hline \multirow{2}{*}{ CHF } & & VT/VF & $39 \%$ \\
\cline { 3 - 4 } & & bradycardia & $62 \%$ \\
\hline Hypertrophic cardiomyopathy & & VT/VF & $36 \%$ \\
\hline Myocarditis & & VT/VF & $11-22 \%$ \\
\hline \multirow{2}{*}{$\begin{array}{l}\text { Arrhythmogenic right } \\
\text { ventricular dysplasia }\end{array}$} & & VT/VF & $23 \%$ \\
\cline { 4 - 4 } & & & $11 \%$ young adults \\
\cline { 3 - 4 } & & & $22 \%$ athletes \\
\hline
\end{tabular}


Table 2: Clinical trials for reduction in mortality due to sudden cardiac death: $\beta$-blockers are useful in MI, post MI and chronic heart failure in decreasing incidence of mortality and SCD. Antiarrhythmic drugs other than $\beta$-blocker have either no effect or increase the mortality. Multicenter Automatic Defibrillator Implantation Trial (MADIT-II); Sudden Cardiac Death in Heart Failure Trial (SCD-HeFT); Cardiomyopathy Trial (CAT); Defibrillators in NonIschemic Cardiomyopathy Treatment Evaluation (DEFINITE); Comparison of Medical Therapy, Pacing, and Defibrillation in Chronic Heart Failure (COMPANION); Antiarrhythmics versus Implantable Defibrillators (AVID)s

\begin{tabular}{|c|c|c|c|c|}
\hline Trial & Reference & $\begin{array}{l}\text { Number of } \\
\text { patients }\end{array}$ & Strategy & Outcome \\
\hline \multicolumn{5}{|l|}{ Primary prevention } \\
\hline \multicolumn{5}{|l|}{ Beta-blockers } \\
\hline Randomized trial & $\begin{array}{l}\text { (Chen et al. } \\
2005)\end{array}$ & 50,000 & $\begin{array}{l}\text { Early administration of } \\
\text { high dose } \beta \text {-blocker } \\
\text { after MI }\end{array}$ & Prevent ventricular fibrillation \\
\hline \multicolumn{5}{|c|}{ Antiarrhythmic drugs } \\
\hline SCD-HeFT & $\begin{array}{l}\text { (Bardy et al. } \\
\text { 2005) }\end{array}$ & & Amiodarone use & No definitive effect on mortality \\
\hline \multicolumn{5}{|l|}{ Statins } \\
\hline MADIT-II & $\begin{array}{l}\text { (Vyas et al. } \\
2006)\end{array}$ & & $\begin{array}{l}\text { Pt. on statin therapy } \\
\text { with ICD }\end{array}$ & Lower rate of VT/VF \\
\hline $\begin{array}{l}\text { Randomized } \\
\text { control trial }\end{array}$ & $\begin{array}{l}\text { (Rahimi et } \\
\text { al. 2012) }\end{array}$ & & $\begin{array}{l}\text { Lipid lowering therapy } \\
\text { with }\end{array}$ & $\begin{array}{l}\text { relative risk reduction in } \mathrm{VT} / \mathrm{VF} \\
\text { and } 10 \% \text { reduction in } \mathrm{SCD}\end{array}$ \\
\hline \multicolumn{5}{|l|}{ Fish Oil } \\
\hline Randomized trial & $\begin{array}{l}\text { (Leaf et al. } \\
\text { 2005) }\end{array}$ & 400 & & $\begin{array}{l}\text { Relative risk reduction of } 31 \% \text { in } \\
\text { VT/VF }\end{array}$ \\
\hline $\begin{array}{l}\text { Multicenter } \\
\text { randomized trial }\end{array}$ & $\begin{array}{l}\text { (Raitt et al. } \\
\text { 2005) }\end{array}$ & 200 & & $\begin{array}{l}\text { More common recurrent rates for } \\
\text { VT/VF }\end{array}$ \\
\hline \multicolumn{5}{|l|}{ ICDs } \\
\hline Randomized trials & $\begin{array}{l}\text { (Goldenberg } \\
\text { et al. 2010) }\end{array}$ & & ICD Vs non-ICD & Increased survival with ICD \\
\hline $\begin{array}{l}\text { Randomized } \\
\text { controlled trials }\end{array}$ & $\begin{array}{l}\text { (Mitchell et } \\
\text { al. 2003) }\end{array}$ & & & $\begin{array}{l}\text { ICDs are superior to } \\
\text { antiarrhythmic drugs }\end{array}$ \\
\hline MADIT II & $\begin{array}{l}\text { (Moss et al. } \\
\text { 2002) }\end{array}$ & & $\begin{array}{l}\text { Pt. with } \mathrm{EF} \leq 30 \% \\
\text { ICD Vs. conventional } \\
\text { therapy }\end{array}$ & $\begin{array}{l}31 \% \text { relative risk reduction of } \\
\text { mortality }\end{array}$ \\
\hline Acute MI Trial & $\begin{array}{l}\text { (Hohnloser } \\
\text { et al. 2004) }\end{array}$ & 700 & $\begin{array}{l}\text { Pt. with } \mathrm{EF} \leq 36 \% \\
\text { ICD Vs. conventional } \\
\text { therapy }\end{array}$ & $\begin{array}{l}\text { At 1year no difference in total } \\
\text { mortality-more arryhtmic deaths } \\
\text { in control and more non } \\
\text { arrhythmic deaths in pt. with ICD }\end{array}$ \\
\hline $\begin{array}{l}\text { Acute MI Trial } \\
\text { (DINAMIT) }\end{array}$ & $\begin{array}{l}\text { (Virk and Ip } \\
\text { 2005) }\end{array}$ & 674 & ICD Vs. non-ICD & $\begin{array}{l}\text { No reduction in overall mortality, } \\
\text { but reduction in arrhythmia }\end{array}$ \\
\hline CAT & $\begin{array}{l}\text { (Bansch et } \\
\text { al. 2002) }\end{array}$ & 104 & $\begin{array}{l}\text { Pt. with } \mathrm{EF} \leq 30 \% \\
\text { ICD versus control }\end{array}$ & No difference in $2-4$ year survival \\
\hline DEFINITE trial & $\begin{array}{l}\text { (Ellenbogen } \\
\text { et al. 2006) }\end{array}$ & 458 & Pt. with $\mathrm{EF} \leq 35 \%$ & $\begin{array}{l}\text { Mortality reduction with ICD at } 2 \\
\text { year follow up }\end{array}$ \\
\hline $\begin{array}{l}\text { COMPANION } \\
\text { trial }\end{array}$ & $\begin{array}{l}\text { (Desai et al. } \\
\text { 2004) }\end{array}$ & 1854 & & $\begin{array}{l}31 \% \text { relative risk reduction in } \\
\text { mortality }\end{array}$ \\
\hline
\end{tabular}




\begin{tabular}{|l|l|l|l|l|}
\hline $\begin{array}{l}\text { Randomized } \\
\text { control trial }\end{array}$ & $\begin{array}{l}\text { (Ghanbari et } \\
\text { al. 2009) }\end{array}$ & 934 & $\begin{array}{l}\text { ICD in HF women } \\
\text { patients }\end{array}$ & $\begin{array}{l}\text { No statistically significant } \\
\text { reduction in SCD }\end{array}$ \\
\hline Secondary prevention \\
\hline AVID & $\begin{array}{l}\text { (Mitchell et } \\
\text { al. 2003) }\end{array}$ & 1016 & $\begin{array}{l}\text { ICD therapy versus } \\
\text { anti-arrhythmics }\end{array}$ & $\begin{array}{l}\text { Overall survival was greater with } \\
\text { the implantable defibrillator }\end{array}$ \\
\hline
\end{tabular}




\section{Figure Legends}

Fig. 1: Thematic representation of the precipitating events and concerns, and measures to improve the incidence of SCD. Ischemic events of the heart results in generation of lethal arrhythmias due to membrane depolarization, intra- and extra-cellular acidification, and cell to cell electrical uncoupling. This leads to ventricular fibrillation (VF) resulting in sudden cardiac death (SCD). DM-diabetes mellitus, HTN-hypertension.

Fig. 2: Lethal arrhythmia in heart leads to cardiac arrest and sudden cardiac death. Ventricular tachycardia/ventricular fibrillation are the precipitating event causing SCD, in ischemia as well as left ventricular failure with reduced ejection fraction. (A) Arrhythmia leading to SCD- a correlation of SCD with different type of arrhythmia. In study with 157 patients with 24 hour ambulatory ECG monitoring suffering from SCD, 70\% had a primarily increase in ventricular premature beats (de Luna et al. 1989). (B) Distribution of arrhythmia in heart failure patients leading to SCD.

Fig. 3: Etiology of sudden cardiac death Terminal VT/VF results in sudden cardiac death. Structural or congenital heart disease, ischemic event or commotio cordis may lead to lethal arrhythmia. AF- atrial fibrillation; VT- ventricular tachycardia; VF- ventricular fibrillation; MI- myocardial infarction; WPW syndrome-Wolf Parkinson White syndrome.

Fig. 4: Correlation of physical activity with sudden cardiac death 


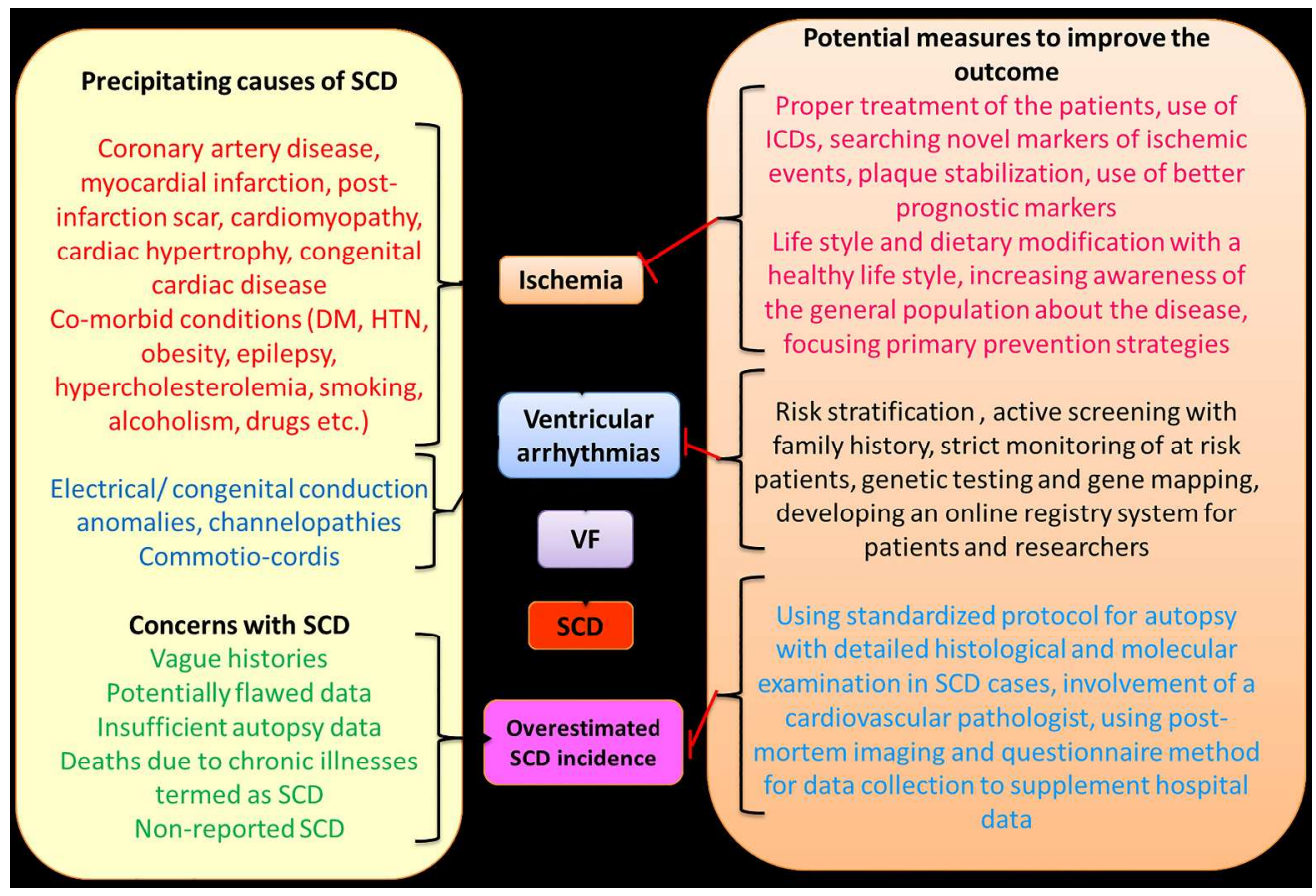

Figure 1

$290 \times 197 m m(300 \times 300$ DPI $)$ 


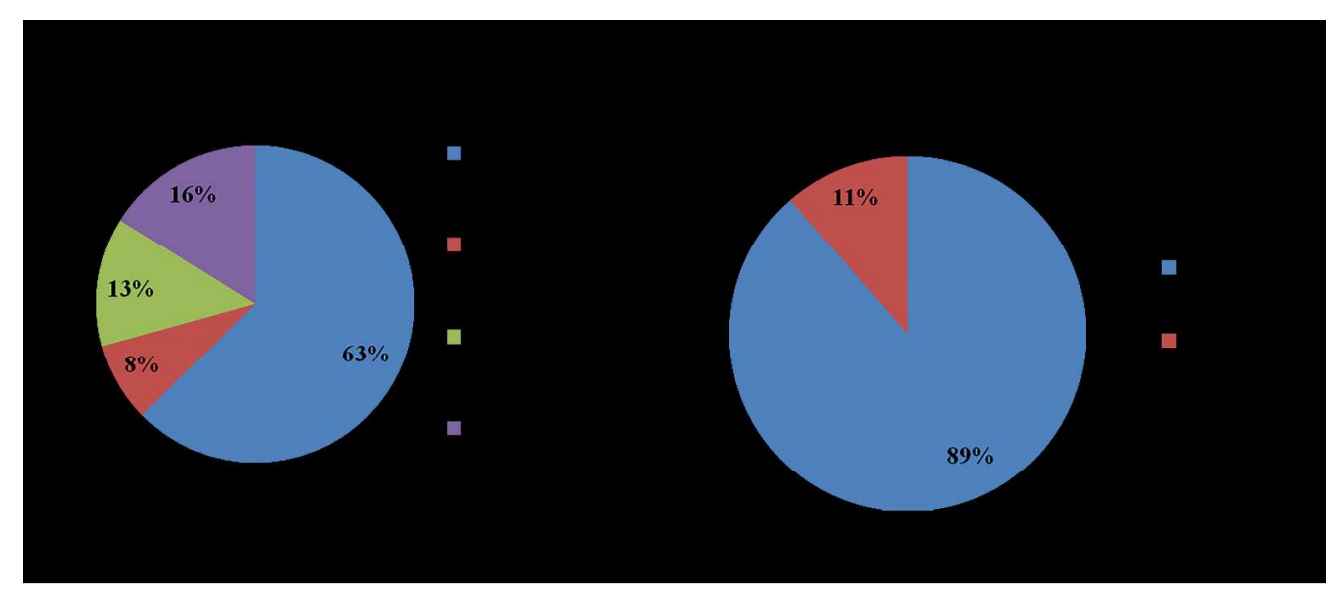

Figure 2.

$226 \times 98 \mathrm{~mm}(300 \times 300 \mathrm{DPI})$ 


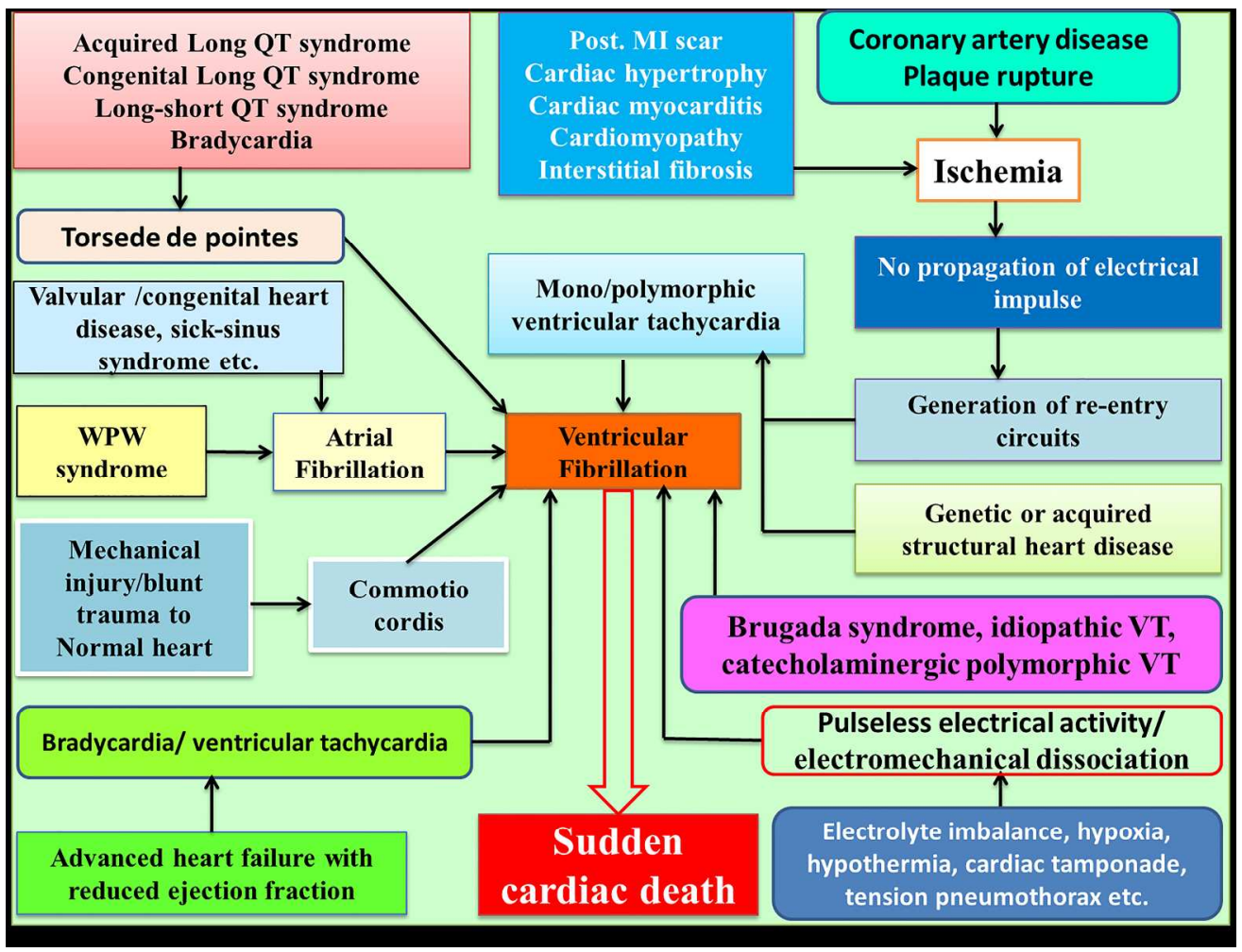

Figure 3.

256x195mm (300 x 300 DPI) 


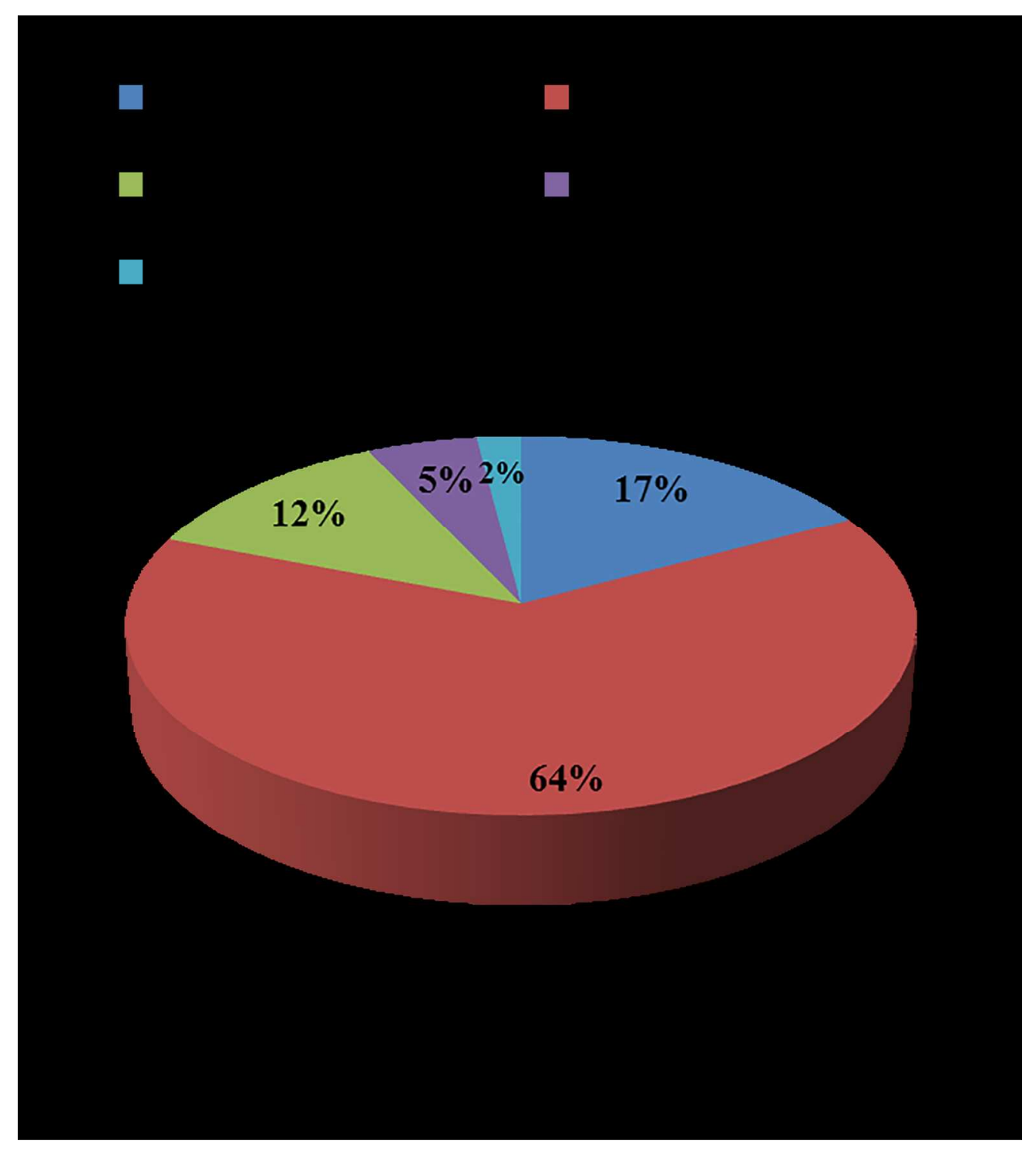

Figure 4.

$112 \times 125 \mathrm{~mm}(300 \times 300$ DPI $)$ 